Revista de Derecho

de la Pontificia Universidad Católica de Valparaíso XXXIII (Valparaíso, Chile, $2^{\text {do }}$ Semestre de 2009)

[pp. $103-148$ ]

\title{
LA PÉRDIDA DEL CONCEPTO ROMANO DE HIPOTECA MOBILIARIA EN LOS DERECHOS MODERNO Y CODIFICADO Y SU RECUPERACIÓN A LO LARGO DE LOS SIGLOS XIX Y XX CON ESPECIAL REFERENCIA AL CASO DE FRANCIA*
}

["Loss of the Roman Concept of Chattel Mortgage in Modern and Codified Laws and its Recovery During the $19^{\text {th }}$ and $20^{\text {th }}$ Centuries with Special Reference to the Case of France"]

\section{Alejandro Guzmán Brito** \\ Pontificia Universidad Católica de Valparaíso, Chile}

\begin{abstract}
RESUMEN
En las modernas codificaciones civiles, la prenda y la hipoteca fueron rígidamente separadas por su modo de constitución, en cuanto la prenda exige entrega de la cosa y la hipoteca una convención sin entrega; y por su objeto, pues la prenda sólo recae sobre muebles y la hipoteca sólo sobre inmuebles. De estos dos puntos de diferencia, sólo el primero es romano, ya que, en cuanto al objeto, la prenda y la hipoteca podían ser constituidas indiferentemente sobre muebles e inmuebles, de manera que, entre otras posibilidades, ahí era dogma común la posibilidad de una hipoteca mobiliaria o sin desplazamiento del mueble pignorado. El Derecho común medieval y
\end{abstract}

\section{AbSTRACT}

In modern civil codifications, the pledge and the mortgage were rigidly separated by their constitution, because the pledge requires delivery of the thing and the mortgage a convention without delivery; and by their aim, as the the pledge fall only on movable and mortgages only on real property. On these two points of difference, only the first is Roman because, on the purpose, the pledge and the mortgage could be formed regardless of movable and immovable, so that, among other possibilities, there was the possibility of common dogma chattel mortgage without displacement of movable. The medieval and modern civil law retained this dogma. But it

* Este trabajo hace parte del proyecto patrocinado por FONDECYT bajo el número 1095068.

** Doctor en Derecho, Universidad de Navarra, España; Profesor titular de Derecho romano de la Facultad de Derecho de la Pontificia Universidad Católica de Valparaíso. Dirección postal: Facultad de Derecho, Pontificia Universidad Católica de Valparaíso, Avenida Brasil 2950, Valparaíso, Chile. Correo electrónico: aguzman@ucv.cl 
moderno mantuvo este dogma. Pero él fue derogado en el Derecho consuetudinario francés (y de otros países europeos), de modo que la prenda de muebles sin su desplazamiento desapareció del horizonte moderno. El Código Civil francés de 1804 (como todos los anteriores y posteriores) recibió la regla consuetudinaria. Pero en el siglo XIX, las necesidades del desarrollo industrial y comercial hicieron ver la conveniencia de adoptar la idea de prenda sin desplazamiento o hipoteca mobiliaria, que poco a poco, $y$ para casos tipificados, fue introducida merced a leyes especiales (hipoteca de naves, prenda agraria, prenda industrial, etc.). En la reforma del Derecho de garantías francés del año 2006, la prenda sin desplazamiento ha sido diseñada con carácter de Derecho común y general; de manera que ahora esa caución sobre muebles puede ser indistintamente con o sin desplazamiento. De esta forma, a fines del siglo XX se ha retornado al Derecho romano clásico.

Palabras clave: Prenda - Hipoteca - Prenda sin desplazamiento - Hipoteca mobiliaria - Prenda (Derecho romano) - Prenda (Derecho común) - Prenda (Derecho codificado) - Prenda (Derecho consuetudinario francés). was repealed in French customary law (and other European countries), so that the piece plegde without displacement disappeared from the modern horizon. The French Civil Code of 1804 (as all previous and subsequent) received the customary rule. But in the nineteenth century, the needs of industrial and commercial development did see the desirability of adopting the idea of nonpossessory pledge, that little by little, and for established cases, was introduced through special legislation (mortgage of ships, agrariaj pledge, garment industry, etc.). In the reform of the French Law of guarantees (2006), the non-possessory pledge was designed as a matter of general and common application, so that now such an order on movables can be either with or without displacement. Thus, in the late twentieth century has returned to the classical Roman law.

KeYwORDS: Pledge - Mortgage Pledge without displacement - Pledge on movables - Pledge (Roman Law) - Pledge (Civil Law) - Pledge (Codified Law) - Pledge (French Customary Law).

\section{PLANTEAMIENTO DEL TEMA}

Los códigos y proyectos de tales emitidos durante la segunda mitad del siglo XVIII y a principios del siglo XIX establecieron una rígida separación dogmática entre la prenda y la hipoteca. Por lo que atañe a la perfección de cada contrato, para la del de prenda fue exigida la entrega de la cosa pignorada al acreedor; mientras que la perfección de la hipoteca se hizo consistir en una convención entre éste y el constituyente de la garantía, manifestada en escrituras públicas, que debían ser inscritas en un registro especial para hacer oponible la garantía a terceros, sin que, en ningún caso, el objeto hipotecado debiera pasar a la tenencia del acreedor. En lo 
concerniente al objeto de cada caución, en algunos casos la prenda pudo recaer indistintamente sobre muebles e inmuebles, pero en otros sólo sobre muebles; mientras que la hipoteca quedó reducida a versar exclusivamente sobre inmuebles y jamás, o sólo en forma muy excepcional -en el caso de la hipoteca universal de bienes- a los muebles. En materia de objeto, pues, aunque solió aceptarse una prenda inmobiliaria, fue invariable el repudio de una hipoteca mobiliaria o prenda sin desplazamiento de la tenencia del objeto pignorado al acreedor. Este último es el punto que realmente interesa para el presente trabajo, porque, desde la segunda mitad del siglo XIX, empezó a desarrollarse un movimiento legislativo al margen de los códigos civiles, y en sentido contrario a ellos, dirigido a introducir la posibilidad de una hipoteca mobiliaria o prenda sin desplazamiento, sólo que con carácter de figura algo anómala y en todo caso especial, porque se la aceptó únicamente para la pignoración de tipos acotados de bienes como garantía del pago de deudas de determinada clase, lo que invariablemente incluía cierta especialidad en los deudores. A fines del siglo XX, este movimiento culminó en una generalización de la hipoteca mobiliaria o prenda sin desplazamiento, con respecto, pues, a todo tipo de bienes para garantizar toda clase de deudas y favorecer a la universalidad de los deudores y acreedores, de manera de haber adquirido la regulación de tales prendas el rango de Derecho común y general.

Lo sorprendente de este interesante fenómeno histórico, que demoró, en términos generales, unos doscientos años en madurar, es que no hubiera sido necesario experimentarlo si los códigos civiles modernos hubiesen recogido el régimen de la prenda y la hipoteca tal cual fue diseñado en el Derecho romano clásico y conservado en el Corpus iuris civilis y en la Ciencia del ius commune medieval y moderno, que tenía concebida una prenda, siempre perfeccionable merced a la entrega de una cosa, que puede ser indistintamente mueble o inmueble; y una hipoteca, que se constituye mediante convención y sin entrega de una cosa, que también puede ser indiferentemente mueble o inmueble; así que en ese ámbito la hipoteca mobiliaria o de prenda sin desplazamiento era una posibilidad general, del todo normal. En algún momento esta configuración romana fue abandonada y se adoptó la rígida separación de la prenda y la hipoteca en cuanto a sus objetos, que expusimos al comenzar, y se hizo imposible la hipoteca mobiliaria o prenda sin desplazamiento; hasta que las necesidades del tráfico jurídico hicieron necesario reintroducirla, como antes quedó dicho. A fines del siglo XX, pues, el Derecho civil, en esta materia, retornó, a impulsos provenientes de la realidad, al Derecho romano clásico, después de haberlo abandonado durante algunos siglos. 


\section{LA PRENDA Y LA HIPOTECA \\ EN EL DERECHO ROMANO ANTIGUO Y MEDIEVAL}

1. El dogma de no ser posible una hipoteca mobiliaria, o prenda sin desplazamiento, sobre muebles, que, como antes hemos dicho en general y examinaremos con más detalle después, tan estrictamente recogieron los códigos y proyectos de tales de la segunda mitad del siglo XVIII y principios del siglo XIX no pertenece, pues, al Derecho romano. En él es exactamente lo contrario, como pasamos a ver.

a) El Derecho clásico conoció dos formas de garantía real como fueron la fiducia (que Gayo denomina "cum creditore contracta"), perteneciente al ius civile -de la que aquí no nos ocuparemos-y el pignus, nacido en el ámbito del edictum (ius preatorium) ${ }^{2}$.

En su configuración original, el pignus consiste en la entrega de una cosa propia por cierto deudor, o un tercero, a un acreedor, para seguridad de su crédito; así que el acreedor adquiere la possessio naturalis o mera tenencia de la cosa pignorada. Este tipo de prenda, perfeccionada merced a la entrega de una cosa y, por ende, con desplazamiento de su tenencia al acreedor, suele ser denominada pignus datum.

En algún momento se abrió paso a la posibilidad de que una simple convención entre un deudor, o un tercero, y un acreedor, en orden a tener una cosa propia por afectada al cumplimiento de una obligación y en seguridad de ésta, produjese el efecto de dejar pignorada esa cosa, sin necesidad de hacerla transitar al acreedor, de modo de permanecer su

${ }^{1}$ Gai. 2,60. Este jurista se refiere a ella y a la actio fiduciae también en estos otros pasajes: Gai. 3,201; 4,62 y 4,182.

${ }^{2}$ Sobre el pignus y sus formas, hace falta una nueva exposición de conjunto. La última disponible pertenece a FrEZzA, Paolo, Le garanzie delle obbligazioni. Corso di Diritto romano (Padova, Cedam, 1963), II: Le garanzie reali, pp. 81-362. Un panorama general: KASER, Max, Das römische Privatrecht (2a edición, München, Beck, 1971), I: Das altrömische, das vorklassische und klassische Recht, pp. 463-473; GUZMÁN BRITO, Alejandro, Derecho privado romano ( $3^{\mathrm{a}}$ reimpresión de la $1^{\mathrm{a}}$ edición, Santiago de Chile, Editorial Jurídica de Chile, 2004), I, pp. 654-670. Algunas monografías concernientes a los puntos que aquí interesan son: MENTXACA, Rosa, La pignoración de colectividades en el Derecho romano clásico (s.l. [pero Bilbao], Servicio Editorial de la Universidad del País Vasco, s.d. [pero 1986]); Löffelmann, Arnd, Pfandrecht und Sicherungsübereignung an künftigen Sachen: Rechtsvergleich zwischen deutschem und römischem Recht (Köln y otras, Böhlau, 1996); RoBles VeLASCO, Luis Mariano, Las hipotecas privilegiadas en el Derecho romano (Madrid, Centro de Estudios Registrales, 2005); KRÄMER, Gerd, Das besitzlose Pfandrecht. Entwicklungen in der römischen Republik und im frühen Prinzipat (Wien y otras, Böhlau, 2007); Braukmann, Michael, Pignus. Das Pfandrecht unter dem Einfluß der vorklassischen und klassischen Tradition der römischen Rechtswissenschaft (Göttingen, Wallstein, 2008). 
tenencia en el deudor, o en el tercero constituyente de la garantía, vale decir, en el pignorante. Este tipo recibe el nombre de pignus conventum. En un momento indeterminado de la época clásica tardía se le aplicó el nombre griego de hypotheca.

Esta diferencia, que se manifiesta en muchos textos, aparece declarada bajo forma general especialmente en dos. Primeramente, en D. 13,7,9,2 (Ulp., 28 ed.): "Proprie pignus dicimus, quod ad creditorem transit, hypothecam, cum non transit nec possessio ad creditorem" ${ }^{3}$. Luego, en D. 13,7,1 pr. (Ulp., 40 Sab.): "Pignus contrahitur non sola traditione, sed etiam nuda conventione, etsi non traditum est" . Por cierto, el discernimiento de cuál tipo prendario utilizar en cada caso era algo que estaba reservado a la libre negociación y elección de los interesados en la operación, sólo limitada por alguna inidoneidad del objeto para poder ser entregado, si es que las partes pensaron en el pignus datum.

En ambos casos, el acreedor, en cuyo favor quedó constituida la prenda, dispone de una formula Serviana (actio Serviana, actio pigneraticia, vindicatio pignoris), de estructura in rem, para reclamar la tenencia de la cosa pignorada contra cualquier persona que actualmente la haya en su poder, aunque sea su dueño. En el caso del pignus datum, tal acción sirve al acreedor para recuperar la cosa cuya tenencia perdió por cualquier causa. Para el evento de un pignus conventum, la acción es especialmente apropiada al fin de empezar a tener la cosa el acreedor, después que el deudor incurrió en mora de pagarle, en función de preparar la venta de dicha cosa, que le permita satisfacerse con el precio que se consiga por ella. Por lo demás, ambas garantías confieren preferencia de pago al acreedor contra los demás acreedores.

b) Ahora bien, lo más relevante para nuestro tema es la verificación de que en el Derecho romano no hubo diferencia alguna entre el pignus datum y el pignus conventum o hypotheca por lo que concierne al tipo de cosas en que una y otra pueden recaer, que no consistiera en su aptitud para poder ser entregadas físicamente. Todo y sólo lo que puede ser físicamente entregado, pues, puede ser objeto de un pignus datum. Pero eso mismo limita naturalmente su procedencia a los corpora, o res corporales en la terminología de Gayo, actuales y presentes; y excluye su procedencia con respecto a los iura, o res incorporales en la misma terminología, a las cosas futuras o que actualmente no existen pero se espera que existan, a la

\footnotetext{
3 "Propiamente llamamos prenda lo que transita al acreedor; hipoteca cuando no pasa ni siquiera la posesión al acreedor".

4 "La prenda se contrae no sólo por la entrega, mas también por una nuda convención, aunque no haya habido entrega" [sc. de la cosa].

${ }^{5}$ Lenel, Otto, EP. $\$ 267$.
} 
pars pro indiviso en una cosa, bien de dominio común, bien de dominio singular, y a las universalidades de cosas (en especial, a todos los bienes presentes y futuros del pignorante, o prenda universal). Ninguna de estas cosas, en efecto, puede ser entregada.

La posibilidad de un pignus conventum, en cambio, amplió considerablemente el ámbito de objetos pignorables. Él puede, de hecho, recaer sobre cualquiera de los objetos que acabamos de indicar como insusceptibles de prenda real, porque es suficiente que las partes convengan en que ellos queden pignorados para que sin más se produzca el efecto de su pignoración. En último término, pues, el único requisito para hipotecarlas es que admitan ser vendidas (aparte, por cierto, de los requisitos generales, como el de estar in commercio, etcétera).

Sin embargo, a partir de esta incongruencia de los ámbitos de cosas pignorables e hipotecables los juristas romanos no vieron ninguna diferencia funcional entre el pignus datum y el pignus conventum o hypotheca, aunque ambos tuvieran la diferencia estructural ya anotada, de constituirse realmente uno y convencionalmente el otro. De hecho, como vimos, el régimen de cada cual fue el mismo. Por tal razón un jurista pudo establecer de esta manera eficaz la equivalencia de ambos tipos prendarios: "Inter pignus autem et hypothecam tantum nominis sonus differt" ". Sólo se trata, pues, de dos nomina para una misma res.

c) En la precedente explicación está implícito que el carácter mueble o inmueble de la cosa que se trata de dar en garantía carece de toda relevancia para orientar la operación hacia un pignus datum o un pignus conventum o hypotheca. Según el Derecho romano, en efecto, tanto se pueda hipotecar un predio o bien entregarlo en prenda, cuanto entregar en prenda un animal o bien hipotecarlo, a libre elección de las partes interesadas. Todo lo que tal vez pueda decirse que haya acaecido en la práctica es esto: i) que de hecho no fuera muy frecuente la prenda real de predios, porque debemos suponer que entonces, como ahora y siempre, son pocos los deudores que están dispuestos a entregar un predio que entretanto puede ser explotado, a menos de pactarse antichresis; ii) que de hecho no fuera muy frecuente la hipoteca de cosas corporales muebles improductivas, como joyas u objetos de arte preciosos, porque también entonces, como ahora y siempre, son pocos los acreedores que están dispuesto a aceptar que se les pignore tales cosas y que al mismo tiempo no queden en su poder. Así que lo normal habrá sido, tratándose de inmuebles, practicar la hipoteca;

${ }^{6}$ D. 20,1,5,1 (Marcian., l. sing. ad form. hypothec.): "Pero entre la prenda y la hipoteca hay tan sólo la diferencia del sonido del nombre". 
y tratándose de muebles improductivos, la prenda ${ }^{7}$. Pero hubo un buen número de muebles que igualmente quedaron sujetos a hipoteca o prenda sin desplazamiento.

Por lo demás, en las fuentes observamos interesantes casos de aplicación de hipotecas mobiliarias: i) la de un rebaño $(\text { grex })^{8}$, que es tratado como universalidad de hecho, así que la hipoteca afecta a las crías nacidas con posterioridad a su constitución y no se extingue por las pérdidas sufridas, como por muerte de algunas cabezas, de modo que hasta puede acaecer que todas las piezas individuales del rebaño resulten sustituidas, sin que se afecte por ello la garantía; ii) la de las mercaderías de un establecimiento de comercio (taberna), que también reciben consideración de universalidad de hecho, de guisa que la venta ordinaria de sus unidades no afecta la

${ }^{7}$ En este contexto debe entenderse lo que dice D. 50,16,238,2 (Gai., 6 duodecim tabul.): “'Pignus' appellatum a 'pugno', quia res, quae pignori dantur, manu traduntur. unde etiam videri potest verum esse, quod quidam putant, pignus proprie rei mobilis constitui" ("Prenda' se llama por 'puño' porque la cosa que se da en prenda se entrega con la mano, de donde que también parece ser verdadero lo que algunos piensan, en orden a que la prenda propiamente se constituye en cosa mueble"). Obsérvese que el texto no expresa que algunos hubieran pensado que sobre muebles no fuera posible constituir hipoteca; sólo expresa que algunos pensaron que la prenda real recae sobre muebles; así que lo único que queda excluido, según ese pensamiento, es la prenda real de inmuebles. Pero él fue minoritario y no prevaleció, aunque en la práctica tal prenda fuera muy rara (salvo si se pactó antichresis). El precedente texto de Gayo tal vez haya influido en el siguiente de Inst. 4,6,7: "Inter pignus autem et hypothecam quantum ad actionem hypothecariam nihil interest: nam de qua re inter creditorem et debitorem convenerit ut sit pro debito obligata, utraque hac appellatione continetur. Sed in aliis differentia est: nam pignoris appellatione eam proprie contineri dicimus quae simul etiam traditur creditori, maxime si mobilis sit; at eam quae sine traditione nuda conventione tenetur proprie hypothecae appellatione contineri dicimus" "Pero en cuanto a la acción hipotecaria, no hay diferencia entre la prenda y la hipoteca; pues acerca de qué cosa se haya convenido entre el acreedor y el deudor que esté obligada por una deuda, una y otra se contienen bajo esta denominación [sc. de acción hipotecaria]. Pero hay diferencia bajo otros respectos: porque en el nombre de prenda decimos que se contiene propiamente aquella cosa que simultáneamente se entrega también al acreedor, sobre todo si es mueble; mas decimos que propiamente se comprende en la denominación de hipoteca, la que sin tradición queda obligada por el sólo convenio"). La influencia se podría ver en la expresión "maxime si mobilis sit" ("sobre todo si es mueble"). En todo caso, este pasaje justinianeo tampoco excluye la hipoteca de muebles y a lo más tiende a reducir la prenda a los muebles, y no en manera dogmática, sino tendencial, como algo de hecho.

${ }^{8}$ D. 20,1,13 pr. (Marcian., l. sing. ad form. hypothec.): "Grege pignori obligato quae postea nascuntur tenentur; sed et si prioribus capitibus decedentibus totus grex fuerit renovatus, pignori tenebitur" ("Obligado en prenda un rebaño, las [sc. cabezas] que nazcan después quedan sujetas [sc. a la prenda]; pero también si, habiendo muerto las anteriores cabezas, todo el ganado fuere renovado, estará sujeto a la prenda”). 
garantía, que, por el contrario, empieza a recaer sobre las nuevas mercaderías ingresadas como reposición?; iii) la de los instrumentos de labranza introducidos por el arrendatario de un predio rústico en éste mismo, para poder explotarlo (desde al menos la época de Catón en el siglo III a.C.), que quedan pignorados a favor del arrendador en garantía del pago de la renta del contrato; más tarde se aceptó una tal prenda sobre los muebles introducidos en un predio urbano arrendado y también sobre los llevados a ciertos establecimientos comerciales, como establos y depósitos; estas últimas prendas incluso tienen carácter tácito ${ }^{10}$; iv) la de los frutos producidos en el predio rústico arrendado, como garantía del pago de la renta al arrendador, que asimismo fue configurada como tácita ${ }^{11}$; v) la de un mueble manufacturado a partir de alguna cosa pignorada, como cuando se hipoteca un bosque y se pacta que la nave fabricada con la madera que de él se obtenga permanezca bajo prenda ${ }^{12}$; vi) la de mercaderías embarcadas para garantizar préstamos marítimos ${ }^{13}$.

${ }^{9}$ D. 20,1,34 pr. (Scaev., 27 dig.): "Cum tabernam debitor creditori pignori dederit, quaesitum est, utrum eo facto nibil egerit an tabernae appellatione merces, quae in ea erant, obligasse videatur? Et si eas merces per tempora distraxerit et alias comparaverit easque in eam tabernam intulerit et decesserit, an omnia quae ibi deprehenduntur creditor hypothecaria actione petere possit, cum et mercium species mutatae sint et res aliae illatae? Respondit: ea, quae mortis tempore debitoris in taberna inventa sunt, pignori obligata esse videntur" ("Como un deudor hubiera dado en prenda cierto bazar a un acreedor, se preguntó si por ese hecho nada se hizo [sc. si es nulo el acto] o si se considera que bajo la denominación de 'bazar' hayan quedado obligadas las mercaderías que en él hubiera habido. Y si, por intervalos, tales mercaderías hubieran sido vendidas y se hubiera comprado otras e incorporado en el bazar y haya fallecido [sc. el dueño del bazar], acaso el acreedor pudo pedir con la acción hipotecaria todas las cosas que ahí se hubieran encontrado, comoquiera que no sólo hayan cambiado las formas de las mercaderías mas también se hayan introducidas otras cosas. Respondió: aquellas cosas que fueron encontradas en el bazar al momento de la muerte del deudor parecen obligadas por la prenda"). También en D. 20,4,6,1 (Ulp., 73 ed.): "Item si quis in merces sibi obligatas [...]" ("También si alguno en las mercadería que le fueron obligadas" [sc. pignorada]).

${ }^{10}$ Véanse: CATO, De agricultura, 146,5-7; 147,4; 149,7; 150,7; D. 2,14,4 pr.; $20,2,2 ; 20,2,3 ; 20.2,4 ; 20,2,6$.

${ }^{11}$ D. $19,2,53$; 19,2,24,1; 20,2,7 pr.; 47,2,62,8; CI. 8,14,3.

${ }^{12}$ D. 13,7,18,3 (Paul., 29 ed.): "Si quis caverit, ut silva sibi pignori esset, navem ex ea materia factam non esse pignori Cassius ait, quia aliud sit materia, aliud navis: et ideo nominatim in dando pignore adiciendum esse ait: 'Quaeque ex silva facta natave sint" ("Si alguien hubiese pactado que se le diese en prenda un bosque, dice Casio que la nave fabricada con la madera proveniente de él no queda en prenda, porque una cosa es la madera y otra el bosque; y por ello dice que se ha de añadir expresamente al dar la prenda: 'y cualquier cosa que haya sido hecha o nacida del bosque'”).

${ }^{13}$ Sobre el punto, véase: Mentxaca, Rosa, La pignoración de colectividades, cit. (n. 2), pp. 231-276. 
Un caso muy interesante e instructivo es vii) el de la hipoteca de piedras de mármol, porque a través de él vemos funcionar la hipoteca mobiliaria en apoyo de operaciones de financiamiento de operaciones comerciales, de una manera nada diferente a como se comporta en los modernos mercados. El aparece examinado en un texto que se conserva en D. 20,4,21,1 (Scaev., 27 dig.), el cual reza así:

"Negotiatori marmorum creditur sub pignore lapidum, quorum pretia venditores ex pecunia creditoris acceperant; idem debitor conductor horreorum Caesaris fuit, ob quorum pensiones aliquot annis non solutas procurator exactioni praepositus ad lapidum venditionem officium suum extendit. Quaesitum est, an iure pignoris eos creditor retinere possit. Respondit secundum ea quae proponerentur posse".
"Se dio crédito a un comerciante de mármoles bajo prenda de unas piedras [sc. de mármol], cuyos precios los vendedores recibieron del dinero del acreedor; el mismo deudor fue arrendatario de unos depósitos del César, por cuyos alquileres, no pagados en algunos años, el procurador nombrado para la cobranza extendió su acción hasta la venta de las piedras. Se preguntó si el acreedor podría retenerlas por derecho de prenda. Respondió que, según lo que se había propuesto, podía”.

Un negociante de mármoles, que necesitaba abastecerse (para el ejercicio de su giro ordinario), pidió la apertura de un crédito a alguien (hoy sería a un banco), de modo que éste pagare a los vendedores de mármol el precio de la compraventa acordada por él con ellos. El comerciante garantizó la devolución de la cantidad acreditada con una prenda sobre las piedras compradas mismas. Seguidamente alquiló unos depósitos imperiales (se supone que para almacenar los mármoles en ellos). Pero dejó de pagar el precio del alquiler; de modo que el procurador imperial, encargado de la percepción de los alquileres, inició la correspondiente cobranza que llegó al punto de ejecutarla sobre las piedras de mármol (depositadas en los almacenes), que debían, pues, ser subastadas. Se consultó a Cervidio Escévola, el juristas que narra el caso, sobre si el acreedor del comerciante, que había financiado su compra de los mármoles, podría retener éstos “por derecho de prenda" (iure pignoris), para satisfacer su crédito con preferencia, pues, al del emperador; y el jurista respondió que el comerciante podía proceder a tal retención ${ }^{14}$. El responsum de Scaevola, pues, validaba completamente esta hipoteca mobiliaria sobre piedras de mármol.

${ }^{14}$ Como la consulta formulada es: "si el acreedor puede retener" ("an [...] creditor retinere possit"), cabría pensar en haberse tratado de un pignus datum, así que las piedras de mármol ya estaban en poder del acreedor, quien precisamente deseaba conservarlas o retenerlas en función de garantía. Pero el contexto no depone a favor 
d) Queda ilustrada, en consecuencia, la afirmación inicial, en orden a haber sido en el Derecho romano completamente indiferente el carácter mueble o inmueble para la constitución de una prenda o una hipoteca, las cuales podían recaer indistintamente sobre uno u otro tipo de bienes. La diferenciación estructural entre ambos negocios estribó sólo en ser necesaria la entrega de la cosa mueble o inmueble en garantía al acreedor, si se trata de prenda; o en la convención de garantía con retención de la cosa mueble o inmueble por el constituyente, cuando el caso era de hipoteca.

2. Los juristas medievales no se apartaron de los conceptos romanos, sobre todo en el punto que aquí interesa, en orden al objeto de la prenda y la hipoteca; $y$, en final de cuentas, aquellos mantuvieron la diferenciación entre ambas figuras tan sólo fundada en haber habido entrega de la cosa pignorada al acreedor (pignus datum) o en haberla retenido el deudor (pignus conventum o hypotheca), sin que la naturaleza mueble o inmueble del objeto influyese ${ }^{15}$. En especial -y es lo que ahora interesa- no negaron la hipoteca sobre muebles-. Con todo, se suscitó alguna variante en sentido contrario entre ciertos canonistas ${ }^{16}$ y todavía en algún escrito de Derecho civil muy antiguo, que no prosperó. Más persistente resultó ser una cierta reluctancia contra la prenda real de inmuebles.

Para ilustración de lo dicho, examinemos algunos textos.

Así en una fuente muy antigua, de mediados del siglo XI, como es el Libellus de verbis legalibus, de autor anónimo, leemos:

"Pignus proprie est quod creditorem transit. [...]. Et dicitur de mobilibus rebus, ut de libro et aliis qui possunt moveri. Hypotheca autem, est pignus vel res supposita obligationi, ut vadium, quod prius obligatur et postea traditur. [...]. Et est proprie de rebus immobilibus, ut de fundo et huiusmodi. Pignorare est aliquid ponere in
"Prenda propiamente es lo que se traspasa al acreedor [...]. Y se dice de las cosas muebles, como de un libro y de otras que pueden ser movidas. Pero la hipoteca es la prenda o cosa sujeta a la obligación, como el 'vadium', que primero es obligada y después entregada. [...]. Y es propiamente de cosas inmuebles, como un fundo y otras

de esta interpretación, pues resultaría muy raro que el comerciante de mármol hubiera comprado las piedras para entregarlas a quien le financió la operación. Conforme: MentXaca, Rosa, La pignoración de colectividades, cit. (n. 2), p. 110.

${ }^{15}$ Acerca de las ideas sustentadas sobre la prenda y la hipoteca por los juristas medievales, véase: Bussi, Emilio, La formazione dei dogmi di Diritto privato nel Diritto comune (diritti reali e diritti di obbligazione) (Padova, Cedam, 1937), pp. 143-165; sobre el punto del objeto mueble o inmueble, pp. 145-149.

${ }^{16}$ Véanse los textos citado por Bussi, E., La formazione dei dogmi, cit. (n. 15), p. 146 nota 1. 
vadio. Repignorare est illud adquietare. Luere idem est quod repignorare, quod vulgo dicitur disguagiare" ${ }^{17}$. semejantes. Pignorar es poner algo en garantía. Repignorar es descargarlo [sc. de la prenda]. Liberar es lo mismo que repignorar, lo que vulgarmente se llama desempeñar".

Los conceptos fundamentales son que la prenda, propiamente hablando, hace transitar la cosa al acreedor; y que en la hipoteca se trata de una cosa que primero es obligada y después entregada. Se observará la imperfección de este último concepto. Da la impresión que en la hipoteca también hay entrega, aunque posterior; y se omite recurrir a la idea de que ella se constituye solo consensu. Sobre estas bases, el texto añade que la prenda se aplica a los muebles, como un libro y otras cosas que pueden moverse; y que la hipoteca es propia de las cosas inmuebles, como un fundo. Así que se excluye tanto la prenda de inmuebles, como la hipoteca de muebles.

Este texto contradice, pues, las ideas romanas. Pero lo más probable es que, en la materia que nos interesa, él recoja ideas de los Derechos consuetudinarios de Francia -que expondremos más adelante ${ }^{18}$, , coincidentes en el punto de reservar la prenda sólo a los muebles y la hipoteca sólo a los inmuebles. Se observará el empleo de vocablos no latinos, provenientes de lenguas vernáculas: dos veces "vadium" y "disguagiare".

La primera, que suele aparecer como "wadium" - "wadiatio", de donde "wadiare", es una palabra que designa cierta forma de prenda entre los pueblos germánicos ${ }^{19}$ y que dio origen a la palabra francesa "gage" ("prenda") ${ }^{20}$, de donde "gager", a través de "gagiare", y también "engager" ("pignorar").

La segunda ("disguagiare") viene de "disvadiare" y dio "dégager" ("desgager", lo contrario de "gager") ${ }^{21}$ y "désengager" (lo contrario de "engager"), con el significado, por ende, de "desempeñar", o sea, de liberar la prenda. "Disguagiare" parece un intermedio anterior a "dégager".

Estos términos, como otros, hacen pensar en una proveniencia francesa

${ }^{17}$ [Anónimo], Libellus de verbis legalibus, "De pignore”, 50, en FitTing, Hermann, Juristische Schriften des früheren Mittelalters (1876, reimpresión Aalen, Scientia, 1965), p. 199.

${ }^{18}$ Véase, el cap. IV.

${ }^{19}$ Sobre ella: Lévy, Jean-Philippe - Castaldo, Andrés, Histoire du Droit civil (Paris, Dalloz, s.d. [pero 2002]), núm. 758, p. 1064.

${ }^{20}$ Ibíd., núm. 521, p. 771.

${ }^{21}$ Du CANGE, Charles du Fresne, Glossarium ad scriptores mediae et infimae Latinitatis (Editio Novissima Insigniter Aucta, Francofurti ad Moenum, Ex Officina Zunneriana, apud Johannem Adamum Jungium. Frankofurti ad Moenum, 1710), IV, s.v. "vadium”, p. 1.364 . 
del texto que los contiene $e^{22}$; y explican que, al menos en el punto de la reserva de los muebles a la prenda y de los inmuebles a la hipoteca, el autor del texto más expusiera Derecho vernáculo que Derecho romano.

Como expresión del pensamiento puramente romanístico se presenta la Glossa de Accursius (†1263). A propósito de D. 50,16,238,1, en donde se dice que la voz "pignus" deriva de "pugno" (= "puño"), porque la cosa que se pignora es entregada con la mano; lo cual parece dar la razón a quienes piensan que la prenda se constituye "propiamente" sobre muebles ${ }^{23}$, el glosador anota sobre la expresión "Pignus proprie" lo siguiente: "Improprie vel abusive etiam immobilis, dummodo detur creditori, quo vero non transit hypotheca" 24 . Accursius no niega que la prenda se puede constituir sobre inmuebles, sólo que ello es "impropio" o "abusivo", en tanto haya que entregar la cosa al acreedor, lo cual no acaece en la hipoteca. Ahora bien, este pasaje sólo muestra una reticencia a aceptar el pignus datum de inmuebles.

En seguida comparece Odofredus (†1265), contemporáneo y rival de Accursius, quien, en relación con D. 20,1,5,1, que afirma no haber diferencia entre prenda e hipoteca más que en el sonido de las respectivas palabras $^{25}$, dice:

" $\$$ iste dicit esse differentia inter pignum et hypothecam solo nomine [...], scilicet quantum ad actionem hypothecariam non differunt [...]. Est tamen in alio differentia, quia pignus re contrahitur, licet hypotheca non re sed consensus contrahitur $[\ldots]$...26.
"Este parágrafo dice haber una diferencia entre la prenda y la hipoteca solo en el nombre. [...], es decir, en cuanto a la acción hipotecaria no difieren [...]. Hay sin embargo, una diferencia en otro punto, porque la prenda se contrae realmente, aunque la hipoteca no realmente sino por el consenso".

El glosador confirma los conceptos que encuentra en su fuente; pero también los complementa con la advertencia de que hay, sin embargo, otra diferencia que no es la nominal, pues mientras la prenda se contrae

${ }^{22}$ Es la opinión de Fitting, H., Juristische Schriften, cit. (n. 17), p. 40.

${ }^{23}$ Véase el texto transcrito en la nota 7.

${ }^{24}$ Accursius, gl. Pignus proprie [D. 50,16,238,2], en Accursius, Glossa in Digestum Novum (Venetiis, B. de Tortis, 1487, reimpresión en Corpus Glossatorum Iuris Civilis, Augusta Taurinorum, Ex Officina Erasmiana, 1968), IX, fol. 192v: "'Prenda propiamente'. Impropia o abusivamente también de inmueble, con tal que sea dado al acreedor, al cual, empero, la hipoteca no transita".

${ }^{25}$ Véase el texto transcrito en la nota 6.

${ }^{26}$ Odofredus, In secundam Digesti Veteris partem, lib. XX: "De pignoribus“, lex "Res hypothecae“, \$ "Inter pignus" [D. 20,1,5,1] (Lugduni, Johannes Pullon, 1523, reimpresión en Opera Iuridica Rariora, Bologna, Forni, 1968), II, 2, fol. 126. 
realmente ( $r e$ ), la hipoteca se contrae consensualmente (consensu). Ahora bien, en cuanto a alguna diferencia concerniente a su objeto mueble o inmueble entre ambas, Odofredus no dice palabra alguna.

También podemos presentar a Iacobus Butrigarius ( $† 1348)$, en quien leemos, con respecto a D. 13,7,1, que sostiene que el pignus se contrae tanto sola traditione, como nuda conventione sin entrega ${ }^{27}$, lo siguiente:

"[...] quantum ad hypothecariam [...] sufficit solus consensus [...], sed quantum ad pignoratitiam, tunc exigitur res [...], et in hoc differt hypothecaria a pignoratitia; item differt a pignoratitia in propria significatione verbi, quia hypothecaria significat ius, tam in rebus mobilibus, quam immobilibus re $<$ non $>^{28}$ tradita" ${ }^{29}$.
“[...] en cuanto a la [sc. acción] hipotecaria [...] es suficiente solo el consenso [...], pero en cuanto a la [sc. acción] prendaria, ahora se exige la cosa [...] y en esto difiere la hipotecaria de la prendaria; también difiere de la prendaria en la significación propia de la palabra, porque la hipotecaria significa el derecho tanto en cosas muebles como inmuebles, <no> habiéndose entregado la cosa”.

El comentarista confirma lo que se lee en la fuente; pero añade algo para nosotros especialmente interesante, que no se dice ahí, en orden a que la acción hipotecaria atañe tanto a cosas muebles como inmuebles.

El también comentarista Albericus de Rosate $(\dagger 1360)$, nuevamente a propósito de D. $20,1,5,1^{30}$, relativo a la diferencia puramente fonética entre prenda e hipoteca, sin embargo, nos trae una voz discorde: "Pignus et hypotheca solo nominis sono differunt, quo ad actionem, non quo ad rem, quia pignus proprie est in re mobili; hypotheca in immobili [...]"31. Este autor escribe bajo la influencia de Inst. 4,6,7: "Inter pignus autem et hypothecam

${ }^{27}$ Véase el texto transcrito a propósito de la nota 4.

${ }^{28}$ Por errata, en este texto cayó un "non", sin el cual carece de todo sentido; o más bien dice algo falso sin discusión: que para la acción hipotecaria hay que haber entregado la cosa.

${ }^{29}$ Butrigarius, Iacobus, In priman et secundam Veteris Digesti partem, "De pignoraticia actione vel contra", lex prima [D. 13,7,1] (Romae, Typis Lepidi Fatii, 1606, II, fol. 144, reimpresión en Opera Iuridica Rariora, Bologna, A. Forni, 1978, XIV, II). Para la restitución del original "no" después caído, véase la nota 28.

${ }^{30}$ Véase el texto transcrito en la nota 6.

${ }^{31}$ Rosate. Albericus de, In secundam Digesti Veteris partem commentaria, rúb. “De pignoribus", etc. ley 5a: "Res hipothecae", \$ “Inter pignus" [D. 20,1,5,1] (Venetiis, 1585, reimpresión en Opera Iuridica Rariora, Bologna, Forni, 1977, XXII, fol. $163^{v}$ ): "Por lo que respecta a la acción, la prenda y la hipoteca solo difieren en el sonido del nombre; no por lo que respecta a la cosa, porque la prenda propiamente es en cosa mueble, la hipoteca en inmueble". 
quantum ad actionem hypothecariam nihil interest" ${ }^{32}$. Para De Rosate, pues, la diferencia únicamente nominal entre prenda e hipoteca es sólo por lo que atañe a la acción, pero no a la cosa. Con respecto a ésta hay una diferencia real: la prenda es sobre cosa mueble y la hipoteca sobre cosa inmueble. Eso no está dicho así en las fuentes, y es una opinión propia de De Rosate. Con todo, el jurista cuida de añadir que esta demarcación fundada en la cosa objeto de cada contrato es sólo cuando se habla "propiamente" de una y otra ("pignus proprie in [...]; hypotheca in [...]"), porque él sabía que, según las fuentes, la hipoteca bien puede recaer sobre muebles y la prenda sobre inmuebles.

En fin, podemos fijarnos en cuanto dice Baldus $(\dagger 1400)$ sobre Inst. $4,6,7$, un texto bastante aislado en donde se observa una tendencia (pero como algo de hecho) a reservar la prenda a los muebles:

"Et inter pignus et hypothecam quo ad actionem hypothecariam danda nulla differentia est, licet in constituendi modo differant, cum hypothecaria sola conventione contrahuntur et in re immobili non tradita vel mobili indisticte. Pignus vero rei mobilis traditionem requerit" 33 .
"Y entre la prenda y la hipoteca, en cuanto a deberse dar la acción hipotecaria, no hay ninguna diferencia, aunque difieran en el modo de ser constituidas, comoquiera que la hipoteca se contrae por la sola convención e indistintamente en cosa inmueble no entregada o mueble. Pero la prenda de cosa mueble requiere tradición".

Baldus repite la habitual observación de que no hay diferencia entre las acciones hipotecaria y prendaria, no bien exista una en la constitución del negocio que funda una y otra acción, comoquiera que la hipotecaria se basa en una convención y la prenda en la entrega de cierta cosa. Pero Baldus cuida de advertir que la convención en que se sustenta la acción hipotecaria recae "indistintamente" sobre cosas inmuebles y muebles que no se entregan.

Podemos, pues, confirmar lo dicho al comienzo, en orden a que los glosadores y comentaristas en general se atuvieron a sus fuentes romanas, sin modificar realmente sus conceptos acerca del objeto de la prenda y la hipoteca. Lo único que puede observarse mejor es su reluctancia a aceptar una prenda real de inmuebles, que implique la entrega del mismo al acreedor. Pero, en cuanto a nuestro tema, confirmaron ampliamente la posibilidad -propia o impropia- de una hipoteca de muebles.

${ }^{32}$ Véase el texto completo en la nota 7.

${ }^{33}$ Baldus, Praelectiones [Commentaria] in quattuor Institutionum libros, $\mathbb{\$}$ "Item Serviana" [Inst. 4,6,7 nota] (Venetiis, 1599, reimpresión en Baldus, Commentaria omnia, Goldbach, Keip, 2004, fol. 44). 
III. LA PRENDA Y LA HIPOTECA

EN LAS CODIFICACIONES DE LA SEGUNDA MITAD DEL SIGLO XVIII Y DE PRINCIPIOS DEL SIGLO XX

1. Las codificaciones modernas eludieron los flexibles criterios establecidos por los juristas romanos y conservados por los medievale, porque a la distinción entre prenda e hipoteca fundada exclusivamente en haber o no entrega de la cosa en garantía al acreedor, añadieron una discriminación concerniente al objeto de una u otra. Los puntos esenciales de la disciplina codificada fueron, pues, éstos: i) mientras la prenda exige que su constituyente entregue la cosa al acreedor, la hipoteca se constituye merced solo a una convención entre ambos, en lo cual no hubo discrepancia con el antiguo Derecho romano; ii) para algunos códigos, la prenda puede recaer tanto sobre muebles como inmuebles, en lo cual tampoco hubo discrepancia; mas, para otros códigos, la prenda no puede recaer sobre inmuebles y quedó limitada, pues, a los muebles, en lo cual sí hubo discrepancia; y iii) la hipoteca sólo puede tener por objeto a los inmuebles, en lo cual concordaron todos los códigos modernos, nuevamente en oposición al Derecho romano. Este último punto es el principal para nuestro tema, porque él implicó haberse hecho imposible una hipoteca mobiliaria o sin desplazamiento de la tenencia del mueble pignorado al acreedor. En esto también concordaron todos los códigos modernos, con una excepción.

Hay ciertamente otra importante diferencia entre la disciplina romana y moderna de la hipoteca. Los romanos carecieron de un sistema de registración de estas garantías, que asegurara la publicidad de los gravámenes hipotecarios. En las legislaciones modernas, de una u otra manera, en cambio, fue adoptada su registración. Pero este punto no afecta mayormente a la dirección de nuestra pesquisa, así que omitiremos referirnos mayormente a él, no sin advertir, empero, que la existencia de registros públicos para los gravámenes hipotecarios en las sociedades modernas hace aún más incomprensible la preterición de las hipotecas mobiliarias, una de cuyas exigencias teóricamente radica precisamente en ser aconsejable y hasta exigible su inscripción, atendida la facilidad que hay para el ocultamiento de unos muebles quedados en poder del deudor, que permita sustraerlos a la ejecución y burlar a los acreedores que gozan de hipotecas sobre ellos.

2. Para ilustrar las afirmaciones generales sobre el régimen prendario adoptado en las modernas codificaciones, antes presentadas, haremos un breve recorrido por los cuerpos legales de la segunda mitad del siglo XVIII y de principios del siglo XIX.

a) Comparece en prime lugar, pues, el Project des Corporis Iuris Fridericiani, nunca aprobado, cuya $1^{\text {a }}$ parte fue publicada en 1749 y la $2^{\circ}$ 
parte en 1751, debidas al jurista Samuel von Cocceius bajo mandato del rey Federico II de Prusia. El tema que aquí interesa resaltar va definido en el siguiente parágrafo de la $2^{\mathrm{a}}$ parte:

"Es differiren aber Pignus und Hypotheca bloß darin, daß ein Pignus oder Pfand nothwendig eine Ueberlieferung oder Traditio erfordere, daher ein Pfand so wol in rebus mobilibus als immobilibus constituiret werden kan; die Hypotheca aber kan auch pacto nudo constituiret werden, und hat bloß in rebus immobilibus statt./ In beiden Fallen erlanget den Creditor ein dingliches Recht und einem Actionem realem, welche Actio hypothecaria genannt wird" 34 .
"Pero la 'prenda' y la 'hipoteca' difieren sólo en esto, en que un 'pignus' o 'prenda' exige necesariamente un traspaso o 'tradición', de donde que una prenda puede ser constituida tanto en 'cosas muebles' como 'inmuebles'; pero la 'hipoteca' también puede ser constituida por 'nudo pacto', y sólo tiene lugar en 'cosas inmuebles'./ En ambos casos el 'acreedor' consigue un derecho real y una 'acción real', que es llamada 'acción hipotecaria'”.

El Project, pues, distingue entre pignus ("Pfand") e hypotheca; y exige entrega de la cosa pignorada al acreedor para constituir la primera, y sólo un nudum pactum para la segunda; añade que el pignus puede recaer indistintamente sobre muebles o inmuebles; pero que la hipoteca sólo sobre inmuebles. Una hipoteca mobiliaria, pues, queda rigurosamente excluida.

b) El siguiente cuerpo que debemos examinar es el Codex Theresianus, un proyecto elaborado por una comisión y revisado por otra, desde 1753, por mandato de la emperatriz María Teresa de Austria, que resultó publicado en 1766 sin tampoco recibir sanción oficial. Ahí leemos la siguiente norma:

"7. Die Pfandschaften werden auf zweierlei Art bestellet, als entweder durch die wirkliche Uebergabe der verpfändete Sache, oder durch die Verschreibung und Behaftung einer Sache zum Unterpfand; erstere heißen eigentlich ein Pfand, Unterpfand, Versatz, leztere aber eine Pfandsverschreibung oder Hypothek. 8. Ein Pfand kann nur an beweglichen Dingen mittelst der wirkliche Uebergabe, eine Hypothek
"7. Las pignoraciones son constituidas de dos maneras, o por el efectivo traspaso de la cosa pignorada, o por la escrituración y sujeción de una cosa a prenda; las primeras se llaman propiamente una prenda, empeño, empeñamiento, pero las últimas, una escrituración de prenda o hipoteca. 8 . Una prenda puede ser adquirida sólo en cosas muebles por medio del efectivo traspaso, una hipoteca, por el contrario,

${ }^{34}$ Zweyter Theil des Corporis Iuris Fridericiani, 2a parte, lib, V, tít. $2^{\mathrm{o}}, \S 1$ [inc. $4^{\mathrm{o}}$ ] (Halle, In Verlegung des Waisenhauses, 1751), p. 133. 
hingegen insgemein nur in liegenden Gütern, und bloß allein in gewissen, in dritten Theil, in siebenten Capitel von Pfandcontracten, in zweiten Artikels, $\$$. XI bestimmten Fällen auch an fahrenden Habschaften mittelst gerichtlicher Verschreibung oder Behaftung erworben werden" 35 . en general, sólo en bienes yacentes, y sólo en ciertos casos determinados en la $3^{a}$ parte, capítulo De los contratos de prenda, artículo 2, $\$ 11$, también sobre haberes circulantes, por medio de escrituración o sujeción judicial".

El Codex Theresianus, pues, distingue dos tipos de pignoración: por la efectiva entrega de la cosa pignorada, que se llama "prenda" ("Pfand", "Unterpfand" o "Versatz"), o por la escrituración y sometimiento de una cosa a pignoración y que se denomina "hipoteca" ("Pfandsverschreibung" o "Hypothek"). Ahora bien -continúa el precepto-, una prenda puede ser adquirida sólo sobre muebles, merced a su efectivo traspaso, mientras que una hipoteca únicamente sobre inmuebles ("liegende Gütter" = "bienes yacentes”). Así que este cuerpo legal fue más estricto que el Project de Cocceius, pues ni siquiera admitió una prenda de inmuebles. Pero -y es lo que nos interesa-, al igual que aquél, el Codex Theresianus tampoco aceptó una hipoteca de muebles. Con todo, este cuerpo legal ofrece una excepción, pues - dice- en ciertos y determinados casos, la hipoteca puede recaer sobre los "haberes circulantes o móviles" ("fahrende Habschaften”), pero merced a escrituración, según se permite en la disposición que se cita en el texto. Esta excepción atañe a la hipoteca universal o sobre todos los bienes presente y futuros del constituyente de la garantía que, como era en el Derecho romano, cubre a los inmuebles y a los muebles del mismo ${ }^{36}$.

Los textos posteriormente derivados del Codex Theresianus, a saber: su reelaboración debida al jurista Bernhard Horten (el llamado "Codex Theresianus nach dem Entwurfe Horten's") ${ }^{37}$ y una nueva reelaboración esta vez obra de Carl Anton von Martini (el llamado "Bürgerliches Gesetzbuch nach dem Entwurfe Martini's”) ${ }^{38}$, no innovaron en su modelo. Por

${ }^{35}$ Codex Theresianus, $2^{\text {a }}$ parte, cap. $30^{\circ}, \$ 2$, núms. 7-8, en Harras, Ritter vON Harrasowsky, Philipp, Der "Codex Theresianus" und seine Umarbeitungen (Wien, Druck und Verlag von Carl Gerold's Sohn, 1884), II, p. 519. Las ideas de estos textos son repetidas en CTher. $3^{a}$ parte, cap. $7^{\circ}$, art. $1^{\circ} \$ 111$, núm. 25 (Ibíd., III, p. 96; y $3^{\text {a }}$ parte, cap. $7^{\circ}$, art. $1^{\circ}, \$ 1$, núms, 3 y 5 (Ibíd., III, p. 98.

${ }^{36}$ Véase: CTher. $3^{\text {a }}$ parte, cap. $4^{\circ}$, art. $2^{\circ}, \$ 11$, núm. 114 , en Harras, cit., III, p. 111. El núm. 115 de ese $₫ 11$ reitera que, fuera de este caso, no cabe ninguna otra hipoteca sobre bienes muebles.

37 “Entwurf Horten's", 2a parte, cap. 26ㅇ, $\$ 1$, en HARRAS, cit., 1886, IV, p. 312; y $3^{\text {a }}$ parte. cap. $7^{\circ}, \$ 6$ (ibíd., p. 359).

38 "Entwurf Martini's", $2^{\text {a }}$ parte, cap. $8^{\circ}, \$ 8$, en HARRAS, $1886, V$, p. 107); y $3^{\text {a }}$ parte, cap. $15^{\circ} \$ 30$ (ibíd., p. 223). 
lo demás, debe decirse lo mismo del Burgerliches Gesetzbuch promulgado por el emperador José II de Austria para West-Galizien en 1797 (después ampliado a la Ost-Galizien) y que se basó en el "Entwurf Martini's"39.

Atendidos estos antecedentes, no es extraño que el Allgemeines Bürgerliches Gesetzbuch austriaco de 1811 dispusiera:

"Um das Pfandrecht wirklich zu erwerben, muß der mit einem Titel versehene Gläubiger, die verpfändete Sache, wenn sie beweglich ist, in Verwahrung nehmen; und, wenn sie unbeweglich ist, seine Forderung auf die zur Erwerbung des Eigenthumes liegender Güter vorgeschriebene Art einverleiben lassen. Der Titel allein gibt nur ein persönliches Recht zu der Sache, aber kein dingliches Recht auf die Sache" ${ }^{40}$.
"Para adquirir realmente el derecho de prenda, el acreedor, premunido de un título, debe tomar la custodia de la cosa, si es mueble; y si ella es inmueble, debe hacer incorporar su crédito en la manera prescrita para la adquisición de la propiedad de bienes yacentes. El sólo título únicamente da un derecho personal a la cosa, pero no un derecho real en la cosa”.

El ABGB. también distingue dos maneras de adquirir el "derecho de prenda" ("Pfandrecht"): si la cosa pignorada es mueble, el acreedor debe "tomarla en guarda o custodia" ("in Verwahrung nehmen"), o sea, recibirla realmente; y si es inmueble, su crédito debe ser incorporado ("einverleiben") en la manera prescrita para la adquisición de la propiedad de los bienes inmueble ("liegende Gütter" = "bienes yacentes"). Con esto último, el ABGB. remite implícitamente a su $\$ 431$, el cual dice que la transferencia de bienes inmuebles exige que el negocio de adquisición ("Erwerbungsgeschäft"), vale decir, el título traslaticio del dominio (venta, permuta, donación, etcétera), deba ser registrado en un "protocolo o libro público" ("offentliches Buch"); y denomina "incorporación” ("Einverleibung” o "Intabulation”) a tal registración. Así que la norma del $\$ 451$, en síntesis, sólo ordena inscribir la hipoteca en un registro formal y no exige el traslado físico de la cosa al acreedor.

Se ve, pues, que el ABGB. sólo conoce una prenda sobre muebles, con desplazamiento posesorio; y una hipoteca sobre inmuebles, sin tal

${ }^{39}$ Bürgerliches Gesetzbuch für West-Galizien, $\$ 519$, en Seiner Majestät des Kaisers Franz Gesetze und Verfassungen im Justiz-Sache für die deutschen Staaten der oesterreichischen Monarchie in den ersten vier Jahren seiner Regierung (Wien, kayserlichköniglichen Hof und Staats-Druckerei, 1817), № 337, p. 456.

${ }^{40}$ Allgemeines Bürgerliches Gesetzbuch für die gesammten deutscher Erbländer der österreichischen Monarchie, $\$ 451$ (Wien, k[aiserlich]-k[önigliche] Hof- und Staatsdruckerey, 1811), pp. 63-64. 
desplazamiento. Él ignora absolutamente la posibilidad de una hipoteca de muebles o prenda sin su desplazamiento.

c) Entretanto, en Prusia nuevamente, el Allgemeines Landrecht für die Preußischen Staaten, promulgado en 1794 por rey Federico Guillermo II, sucesor de Federico II, también había definido sus conceptos. En primer lugar, identificó un general "derecho de prenda" ("Unterpfandrecht"), de carácter real sobre cosa ajena, constituido para seguridad de un crédito ${ }^{41}$. Enseguida: "Geschieht die Einräumung dieses dinglichen Rechts durch Uebergabe der Sache: so ist ein Pfandrecht im engern Sinne" "42. Esta "prenda en sentido restringido" ("Pfandrecht im engern Sinne") puede recaer tanto sobre muebles como sobre inmuebles: "Das Pfandrecht im engern Sinne kann mittelst Einräumung des Besitzes, auf bewegliche und unbewegliche Sachen bestellt werden" ${ }^{33}$. Si se trata de cosas muebles, basta la simple entrega sin forma adicional alguna ${ }^{44}$; pero tal entrega no es suficiente para la prenda en cosas inmuebles ${ }^{45}$; y es necesaria una inscripción en el "Hypothekenbuch" 46.

Por el contrario: "Geschieht dieselbe durch gerichtliche Eintragung auf Gründsctüke, und solche Gerichtigkeiten, welche die Gesetze den unbeweglichen Sachen gleich achten: so hat der Gläubiger das Recht einer Hypothek"47. Ya en este artículo inicial se deja en claro que la hipoteca sólo recae sobre inmuebles. Lo cual es reafirmado más adelante: "Hypothekenrechte können nur auf Grundstücke und solche Gerechtigkeiten, welche die Gesetze den unbeweglichen Sachen gleich achten, erworben werden " ${ }^{48}$. Pero enseguida se

${ }^{41}$ ALPS., $1^{\text {a }}$ parte, tít. $20^{\circ}$, sec. $1^{\text {a }}, \$ 1$, en Allgemeines Landrecht für die Preußischen Staaten von 1794 (edición de Hattenhauer, Hans, Frankfurt am Main - Berlin, Metzner, 1970), p. 286.

${ }^{42}$ Ibíd., $\$ 7$, en $A L P S$., cit., p. 286: "Si la concesión de este derecho real acaece por el traspaso de la cosa, se trata de una prenda en sentido restringido".

${ }^{43}$ Ibíd., $\$ 71$, en ALPS., cit., p. 288: "El derecho de prenda en sentido restringido puede ser constituido sobre cosas muebles e inmuebles, por medio de la concesión de la posesión".

${ }^{44}$ Ibíd., $\$ 94$, en ALPS., cit., p. 289.

${ }^{45}$ Ibíd., $\$ 99$, en ALPS., cit., p. 289.

${ }^{46}$ Ibíd., $\$ 100$, en ALPS., cit., p. 299.

${ }^{47}$ Ibíd., $\$$ 8, en $A L P S$., cit., p. 286: "Si el mismo [sc. el derecho real de prenda] acaece por medio de una inscripción judicial sobre predios, y otros derechos que las leyes igualmente miran como cosas inmuebles, entonces el acreedor tiene un derecho de hipoteca".

${ }^{48}$ Ibíd., $\$ 390$, en ALPS., cit., p. 299: "Los derechos de hipoteca sólo pueden ser adquiridos sobre predios y ciertos derechos que las leyes igualmente miran como cosas inmuebles". 
añade que también la hipoteca, igual que la prenda de inmuebles, exige una inscripción en un "Hypothekenbüch" 49 .

El ALPS., pues, conservó el modelo del antiguo Project de Cocceji, en orden a prever la posibilidad de un derecho de prenda con desplazamiento posesorio de muebles e inmuebles ("derecho de prenda en sentido restringido" - "Pfandrecht im engern Sinne"), si bien cuando recae sobre inmuebles se hace necesaria una inscripción; y un derecho de hipoteca, limitado exclusivamente a inmuebles, que se constituye por medios solemnes, inscripción en registros especiales incluida, y que no exige un desplazamiento posesorio al acreedor. También, por ende, el ALPS. ignora la posibilidad de una hipoteca mobiliaria o sin desplazamiento.

d) El Code Civil des Français $(1804)^{50}$, en fin, no procedió de manera distinta que sus predecesores prusianos. El tít. $17^{\circ}$ del libro III de ese cuerpo legal regula un genérico contrato que denomina "nantissement"; $\mathrm{y}$ "[...] par lequel un débiteur remet une chose à son créanciar pour sûreté de la dette" 51 . El "nantissement", pues, tiene carácter de contrato real, porque se perfecciona por la entrega ("remise") de la cosa. El artículo 2072 añade que el "nantissement" de una cosa mueble se llama "gage"; y el de una cosa inmuebles, "antichrèse". Por otro lado se presenta la "hypothèque", tratada en el cap. $3^{\circ}$ del tít. $18^{\circ}$ del mismo libro III; y que define como "[...] un droit réel sur les immeubles affecté à l'acquittement d'une obligation" ${ }^{2}$. El artículo 2118 insiste en que sólo son susceptibles de hipoteca los bienes inmuebles (y el usufructo de tales bienes). Según el artículo 2127, ella debe ser constituida por acto auténtico antes dos notarios o ante uno y dos testigos. Desde que la hipoteca así constituida es inscrita en los registros del Conservador de Hipotecas, el acreedor goza de una preferencia de pago sobre el bien hipotecado en su favor.

En síntesis, para el Code Civil, el "nantissement" se caracteriza por imponer el desplazamiento de la cosa, mas puede ser sobre muebles ("gage") $)^{53}$ o inmuebles ("antichrèse"54); mientras que la "hypothèque" recae sólo

\footnotetext{
${ }^{49}$ Ibíd., $\$$ 391, en ALPS., cit., p. 299.

${ }^{50}$ Code Civil des Français (Édition originale et seule officielle, Paris, Imprimerie de la République, 1804).

${ }^{51}$ CCFr., art. 2071, en Code Civil, cit, p. 499: "por el cual un deudor entrega una cosa a su acreedor, para seguridad de la deuda".

${ }^{52}$ CCFr., art. 2114, en Code Civil, cit, p. 512: "[...] un derecho real sobre los inmuebles afectados al cumplimiento de una obligación”.

${ }^{53} \mathrm{El}$ artículo 2119, en Code Civil, cit, p. 513, insiste: "Les meubles n'ont pas de suite par hypothèque”. Volveremos sobre esta disposición.

${ }^{54} \mathrm{La}$ anticresis del CCFr., empero, no confiere un derecho real ni una preferencia de pago sobre el inmueble, a menos que se haya constituido una hipoteca además (art. 2091, en Code Civil, cit, pp. 503-504).
} 
sobre inmuebles, sin que deba haber desplazamiento. Nuevamente debe ser observado que este cuerpo legal ignora la posibilidad de una hipoteca mobiliaria o sin desplazamiento.

3. Es un rasgo común a todos los cuerpos legales precedentemente examinados: i) distinguir la prenda de la hipoteca; ii) exigir la entrega de la cosa para la constitución de la prenda; iii) no exigir la entrega de los bienes hipotecados; y iv) limitar la hipoteca a los inmuebles. Algunos de ellos permitieron que la prenda pudiera tener por objeto tanto mueble como inmueble (Project de Cocceji, ALPS. y Code Civil); otros limitaron la prenda a los muebles (Codex Theresianus y sus derivados, incluso el ABGB.). Con ello queda corroborado lo que se expresó al comenzar, en orden a que ninguno de los cuerpos legales examinados aceptó o reconoció una hipoteca de muebles o prenda sin su desplazamiento. En ello ciertamente hubo completa coincidencia.

Sin embargo, merece ser destacado que a este régimen de exclusión de la hipoteca mobiliaria, uniformemente adoptado por los cuerpos legales que antes se estudió, hizo excepción el Codex Maximilianeus Bavaricus Civilis, promulgado en 1756 por el príncipe elector Maximiliano José III de Baviera y cuya elaboración se debió al canciller Alois von Kreyttmar. En él se lee:

"Das Recht, welche der Glaubiger zur Sicherheit seiner Forderung in des Schuldners Vermögen zum Theil oder ganz überkommt, heißt ein Unterpfand, und zwar wenn das verpfändete Gut würklich ausgeantwortet und übergeben wird, so nennt man es ohne Unterschied beweglich- oder unbeweglicher Gütern ein Faust-Pfand, oder da solches nur mittels blosser Verschreibung ohne Extradition geschiehet, eine Hypothec $[\ldots]^{\text {" } 55}$.
"El derecho que un acreedor recibe en el todo o en una parte del patrimonio del deudor para seguridad de un crédito, se llama prenda; y cuando el bien pignorado responde realmente $y$ es entregado se llama, sin diferencia de bienes muebles o inmuebles, una prenda manual, o una hipoteca, si tal acaece sólo por medio de una pura inscripción sin 'tradición"”.

La norma define primariamente una figura, que denomina "prenda" ("Unterpfand"), como el derecho del acreedor en el todo o una parte del patrimonio de su deudor, para seguridad de su crédito. Y para explicar ese concepto, añade que cuando el bien pignorado responde realmente porque

${ }^{55}$ CMBC., 2a parte, cap. $6^{\circ} \$ 1$, en Codex Maximilianeus Bavaricus Civilis oder Neu Verbessert und Ergänzt Chur-Bayrisches Land-Recht (München, Johann Jacob Vötter, 1756), p. 127. 
fue entregado (al acreedor), aquella figura se llama "prenda manual" ("FaustPfand"); e "hipoteca" ("Hypothec") si tal (es decir, que el bien responde realmente) acaece sólo por medio de una mera inscripción sin tradición. Con esto, el CMBC. se limita a verter lo conceptos romanos, que distinguen un pignus datum y un pignus conventum. Pero en medio de este discurso se inserta la frase: "sin distinción de bienes muebles o inmuebles" ("ohne Unterschied beweglich-oder unbeweglicher Gütern"). Ahora bien, esta frase parece valer tanto para el Faust-Pfand como para la Hypothec ${ }^{56}$. De acuerdo con ello, la prenda y la hipoteca pueden recaer indistintamente sobre muebles o inmuebles. De hecho, en las demás normas que integran el cap. $6^{\circ}$ nada hay que mueva a pensar que la hipoteca no puede incidir sobre muebles. Se trata, por consiguiente, de una señalada excepción a la actitud que asumieron todos los cuerpos legales de la época que estamos estudiando.

\section{EL ABANDONO DE LA HIPOTECA INMOBILIARIA O PRENDA DE MUEBLES SIN DESPLAZAMIENTO EN EL DERECHO CONSUETUDINARIO ANTERIOR A LA CODIFICACIÓN}

1. ¿Cómo fue que los códigos modernos, con la excepción señalada del CMBC., llegaron a desconocer el dogma romano y medieval de poderse constituir prenda sobre muebles sin su desplazamiento? Para el caso de Francia, el testimonio de juristas de los siglos XVI, XVII y XVIII es coincidente en cuanto a que el dogma opuesto hubo de ser introducido por las coutumes; así que la respuesta a la pregunta inicial hay que formularla bajo la idea de que los codificadores franceses no concibieron el designio de innovar en la materia: haber adoptado la hipoteca mobiliaria en el Code Civil hubiera sido una reforma al Derecho vigente, para fundar la cual no hallaron razones. De hecho, el asunto no fue ni siquiera discutido entre los miembros de los cuerpos que revisaron el proyecto de código ${ }^{57}$, de modo que aquellos se dejaron gobernar sin crítica por la inercia.

En este punto, nuestra tarea debería consistir en conducir un estudio sobre el Derecho de prendas e hipotecas vigente en Prusia, Austria y Francia antes de la codificación en cada uno de esos países para verificar la existencia o inexistencia de una hipoteca mobiliaria o prenda de muebles sin desplazamiento posesorio y establecer en qué medida cada código o

\footnotetext{
${ }^{56} \mathrm{La}$ estructura del conjunto que interesa es, pues, ésta: "Das Recht [...], heißt ein Unterpfand, und zwar [...] so nennt man es ohne Unterschied beweglich-oder unbeweglicher Gütern ein Faust-Pfand, oder [...], eine Hypothec".

${ }^{57}$ Así lo muestra el examen de FenET, Pierre-Antoine, Recueil complet des travaux préparatoires du Code Civil (Paris, Videcoq, 1836), XV, en donde va editada la discusión de los proyectos sobre "nantissement" e "hypothèque".
} 
proyecto de tal se adaptó a ese Derecho. Pero un trabajo así está fuera de nuestras perspectivas actuales $y$, por ello, optamos por conferir al presente un carácter exploratorio, cuyas líneas generales eventualmente puedan servir como modelo general a otros estudiosos. Lo que haremos será verificar los testimonios de algunos juristas franceses acerca del Derecho consuetudinario de prendas e hipotecas, en el punto que aquí nos interesa.

2. Pero no nos faltan indicios de que cuanto habremos de verificar para Francia acaeció similarmente en otras latitudes.

a) Así, por ejemplo, disponemos de la siguiente declaración de Hugo Grotius (1583-1645):

"Inter pignus autem \& hypothecam tantum nominis sonus differt. Nam \& oppignari ager dicitur quamquam a pugno orta pignoris vox [...]. Frequentior tamen usus recepit ut in re mobili pignus diceretur immobili hypotheca $[\ldots]{ }^{\prime 58}$.
"'Entre prenda, sin embargo, e hipoteca hay tan sólo la diferencia del sonido del nombre'. Pues también se dice dar en prenda un predio, aunque la voz "pignus” se origina en 'pugnus' [sc. 'puño'] [...]. Más frecuentemente, empero, el uso recibió que se diga prenda con respecto a las cosas muebles e hipoteca con respecto a las inmuebles $[\ldots] "$.

Grotius comienza por recordar el contenido de D. 20,1,5,1, ya antes citado por nosotros, según el cual entre prenda e hipoteca hay tan sólo la diferencia derivada del sonido de cada una de esas palabras. En seguida advierte que también se puede dar la tierra (ager) en prenda. Y termina por destacar que el uso tiene recibido hablar de prenda con respecto a los muebles y de hipoteca en relación con los inmuebles; y que este uso es "más frecuente" que la sinonimia aducida por el texto romano. Es posible que con "usus", Grotius aluda al usus loquendi; pero es evidente que un tal modo de hablar tuvo que corresponder a una realidad acerca de las figuras designadas por las palabras involucradas. En la Inleidinghe tot de Hollandsche Rechts-gheleertheydt (1631), sin embargo, explica que una hipoteca especial puede recaer sobre muebles o inmuebles ${ }^{59}$; añade que

${ }^{58}$ Grotius, Hugo, Florum sparsio ad jus Iustinianeum, "De pignoribus et hypothecis”, L. Res hypothecae (Neapoli, Ex Officina V. Manfredii, 1577), p. 124.

${ }^{59}$ Grotius, Inleidinghe, lib. II, cap. 48 , núm. 25, en El Mismo, The Jurisprudence of Holland, The text Translated with Brief Note and a Commentary by Robert Warden Lee (2a edición, 1953, reimpresión Aalen, Scientia, 1977), p. 285: “A special hypothec may relate to movable or to immovable property" ("Una hipoteca especial puede referirse a la propiedad mueble o inmueble"). 
la de muebles tiene lugar con o sin entrega ${ }^{60} ; \mathrm{y}$ aclara que cuando es sin entrega, ella tan sólo vale con respecto al deudor, pero no perjudica a los demás acreedores, a menos que haya sido otorgada ante tres testigos o ante un notario y dos testigos ${ }^{61}$. En cuanto al régimen de esta prenda, incluso cuando fue otorgada formalmente, si acaece que la cosa mueble llega a manos de terceros queda libre del gravamen ${ }^{62}$. Esto significa que la prenda mobiliaria sólo es eficaz mientras el mueble pignorado esté en poder del deudor y que deja de serlo cuando sale de su poder. Más adelante veremos que lo mismo ocurre en el "Droit Français coutumière".

b) Para el usus modernus Pandectarum, disponemos de la siguiente afirmación del jurista alemán Johan Heinrich Berger (1657-1732):

"Pignus diferre ab hypotheca, in primis, ratione modi constituendi: pignus constituitur traditione, hypotheca autem sola conventione [...]; at, ratione obiecti, pignus et hypotheca non differunt, cum utrumque in rebus aeque mobilibus ac immobilibus constituatur, quamquam pignus mobilem, hypotheca immobilium esse solet" ${ }^{\prime \prime 3}$.
"La prenda difiere de la hipoteca, en primer lugar por razón del modo de ser constituida: la prenda se constituye por entrega, pero la hipoteca por la sola convención [...]; mas, por razón del objeto, la prenda y la hipoteca no difieren, comoquiera que una y otra se constituyen igualmente sobre cosas muebles e inmuebles; aunque la prenda suele ser sobre las muebles, [y] la hipoteca sobre las inmuebles".

${ }^{60}$ Ibid., núm. 26: "A special hypothec of movable property may take place with delivery or without delivery" ("Una hipoteca especial sobre propiedad mueble puede tener lugar con entrega o sin entrega").

${ }^{61}$ Ibíd., núm. 28: "Without delivery it is valid though merely underhand so far as concerns the debtor, but not to the prejudice of other creditors, unless the hypothec was executed before three witnesses or before a notary and two witnesses" ("Es válida sin entrega, aunque meramente privada, en cuanto concierne al deudor, pero no en perjuicio de otros acreedores, excepto si la hipoteca fue constituida ante tres testigos $\mathrm{o}$ ante un notario y dos testigos").

${ }^{62}$ Ibíd., núm. 28 (p. 287): "But in case the movable property by lawful title is come into a third hand, then the property is free and unburdened [...]" ("Pero en el caso en que la propiedad mueble [sc. hipotecada] con título legal vaya a terceras manos, entonces la propiedad se hace libre y sin carga"). Añade, empero, que en la Renania hay una disciplina especial: en la venta de un mueble, el vendedor puede estipular una prenda sobre la cosa vendida, para garantizar el pago del precio, y esta garantía puede ser opuesta a terceros.

${ }^{63}$ Berger, Ioannes Henricus, Oeconomia iuris ad usum hodiernum accomodati, lib. II, tít. 5, I, nota $2^{\text {a }}$ (8a edición, Lipsiae, Libr. Weidmann, 1801), I, pp. 541542. 
La expresión “esse soleat” es más propia para introducir la descripción de un uso.

3. Por otro lado, algunos iusnaturalistas modernos se mostraron predispuestos en contra de la hipoteca mobiliaria.

a) Tal vemos, por ejemplo, en Samuel Pufendorf (1632-1694):

"Solet ius Romanum distinguere inter pignus specialiter sic dictum, et hypothecam; quorum illud constituitur rei traditione, haec autem constat nuda assignatione boni alicuius potissimum inmobilis, ex qua solutione non facta, suum nascisci possit creditor. Nam res mobiles nuda hypotheca obligare inconveniens est, cum facile possint removeri, et sic creditori nequeant securitatem praestare" ${ }^{64}$.
"El Derecho romano suele distinguir entre la prenda propiamente dicha y la hipoteca; de las cuales, aquella se constituye por la entrega de la cosa, ésta, en cambio, consta por nuda designación de los bienes de alguien, principalmente inmuebles, en virtud de la cual, no hecho el pago, el acreedor los hace suyos. Pues es inconveniente obligar las cosas muebles mediante nuda hipoteca, comoquiera que sea fácil amoverlas, y así no sean capaces de prestar seguridad al acreedor”.

En este texto encontramos una discusión directa acerca de la posibilidad de obligar cosas muebles mediante nuda hypotheca. Pufendorf primeramente describe la regla romana, que distingue la prenda y la hipoteca, según que la garantía se constituya por la entrega de la cosa o por lo que aquél denomina "nuda assignatio" de ciertos bienes -"principalmente inmuebles" ("potissimum inmobilis") añade-. Enseguida sienta su parecer: una hipoteca mobiliaria le parece inconveniente debido a la facilidad con que los muebles pueden ser mudados de localización ("removeri"), de modo de no poder prestar ninguna seguridad al acreedor.

b) Algo semejante hallamos en Christian Wolf (1679-1745):

"Jus pignoris ac hypotheca constitui potest tam in re mobili, quam immobili; immo in re incorporali. Illud tamen securius constituitur in re mobili, hoc autem in immobili. Etenim jus pignoris constituitur in re tradita, jus hypothecae in re non tradita. [...]./ Quoniam vero per se patet, magis
"El derecho de prenda e hipoteca se puede constituir tanto sobre cosa mueble como inmueble; incluso en cosa incorporal. Pero aquél se constituye más seguramente sobre cosa mueble, éste, en cambio, sobre inmueble. Pues el derecho de prenda se constituye en cosa entregada, el derecho de hipoteca

${ }^{64}$ Pufendorf, Samuel, De iure naturae et gentium libri octo, lib. V, tít. 10, $\$ 16$ (Francofurti et Lipsiae, ex officina Knochio-Eslingeriana, 1759, reimpresión Frankfurt am Main, Minerva, 1967), I, p. 793. 
prospectum esse securitati creditoris, si ipse rem mobilem sibi oppignoratam detineat, quam si eum penes se habeat debitor, consequenter si ea ipsi tradita fuerit; non magis autem prospectum sit securitati creditoris, sive ipsi rem immobilem detineat, sive debitor, jus pignoris securius constituitur in re mobile, hypotheca in immobile" ${ }^{65}$. en cosa no entregada [...]./ Porque, empero, como es evidente por sí mismo, mira más a la seguridad del acreedor si él mismo detenga la cosa mueble que le fue pignorada, que si ella la tenga el deudor junto a él, es consecuente, que si ella le fue entregada, no más se mire a la seguridad del acreedor que el mismo o el deudor detenga la cosa inmueble, el derecho de prenda se constituye más seguramete en cosa mueble y la hipoteca en inmueble".

Wolf comienza por reconocer que la prenda y la hipoteca pueden constituirse sobre muebles e inmuebles. Pero afirma que la prenda se constituye "más seguramente o con mayor seguridad" ("securius") sobre cosa mueble y la hipoteca sobre cosa inmueble. La razón es que la prenda se perfecciona por la entrega, que no tiene lugar en la hipoteca; y resulta a su parecer evidente que mira más a la seguridad del acreedor si él mismo detenta la cosa mueble que le fue pignorada, porque le fue entregada, que no si la detenta el deudor en su poder. En cambio, es indiferente para la seguridad del acreedor que la cosa inmueble afectada a la garantía esté en manos del acreedor o del deudor. De donde que Wolf deduzca que se constituye con más seguridad sobre muebles una prenda y sobre inmuebles una hipoteca.

c) El argumento de la inseguridad que ofrece la hipoteca mobiliaria al acreedor es, por consiguiente, el argumento que en común sirve a Pufendorf y a Wolf para desconfiar de ella. De esta manera, si las costumbres tenían abandonada la práctica de la hipoteca mobiliaria y autores de prestigio en el siglo XVIII como Pufendorf y Wolf, a los que seguramente se podrá añadir otros, desconfiaban de ella, los codificadores modernos no tenían razones para modificar el estado de hecho con que se encontraban en la realidad.

4. Según el designio preanunciado, vamos a ocuparnos ahora del caso francés.

Para diseñar su sistema de garantías reales, que, como vimos, distingue

${ }^{65}$ Wolf, Christian, Ius naturae método scientifica pertractatum, $5^{\circ}$ parte, cap. $5^{\circ}$, $\$ 1162$ (Halae Magdebvrgicae, in Officina Libraria Rengeriana, 1746, pp. 784-785; reimpresión en Wolf, Christian, Gesammelte Werke, Herausgegeben und Bearbeitet von L. École (y otros), II. Abteilung: Lateinische Schriften, Band 21: Jus naturae, Herausgegeben und Bearbeitet por Marcel Thomann, Hildesheim, Georg Olms Verlagsbuchhandlung, 1968). 
un genérico “nantissement”, que impone la entrega de la cosa en garantía, y asume dos tipos: el "gage" sobre muebles y la "antichrèse" sobre inmuebles; ambos frente a la "hypothèque", constituida exclusivamente sobre inmuebles, que no se entregan al acreedor, pero que exige un acto auténtico y una inscripción en registros públicos; para ello, los codificadores se fundaron en Robert-Joseph Pothier (1669-1772). Este gran jurista escribió dos tratados sobre garantías reales: primeramente un Traité du contrat de nantissement publicado en 1767; y después un Traité de l'hypothèque, que vio la luz en 1776 , o sea, póstumo.

a) En el primero dice que:

“1. On peut définir le contrat de nantissement, un contrat, par lequel un débiteur, ou un autre pour lui, donne au créancier une chose pour la détenir par devers lui pour la sûreté de sa créance; et le créancier s'oblige de la lui rendre après que sa créance aura été acquittée. 2. La chose, qui est donnée par ce contrat au créancier, s'appelle nantissement; elle s'appelle aussi gage, et en latin pignus"66.
“1. Se puede definir el contrato de 'nantissement' como un contrato por el cual un deudor, u otro por él, da a un acreedor una cosa para tenerla en su poder para la seguridad de su crédito; y el creedor se obliga a devolvérsela después que su crédito haya sido pagado. 2. La cosa que es dada por este contrato al acreedor se llama 'nantissement'; se llama también prenda y en latín 'pignus".

La figura tiene carácter real, vale decir, consiste en entregar una cosa al acreedor para que la tenga en garantía de su crédito. Más adelante, al estudiar los objetos sobre los que puede recaer el "nantissement", expresa:

"Ce sont les meubles corporels qui sont ordinairement l'objet du contrat de nantissement. [...]. Néanmoins les héritages peuvent être aussi l'objet de ce contrat $[\ldots]$. C'est ce qui arrive, lorsqu'on met un créancier en possession d'un héritage, pour qu'il en perçoive les fruits en déduction de ses créances, jusqu'au parfait paiement, dont il doit rendre compte à celui qui le lui a donné en nantissement" ${ }^{17}$.
"Ordinariamente son el objeto del contrato de 'nantissement' los muebles corporales [...]. Sin embargo, los predios también pueden ser objeto de este contrato [...]. Lo que acaece cuando se pone a un acreedor en posesión de un inmueble, para que perciba los frutos en deducción de sus créditos, hasta el pago completo, de lo cual él debe dar cuenta a aquel que le ha dado en 'nantissement"'.

${ }^{66}$ Pothier, Robert-Joseph, Traité du contrat du nantissement, artículo preliminar, núms. 1-2, en Euvres de R.-J. Pothier contenant les traités du Droit Français (edición de Bugnet, M., Paris, H. Plon - Cosse et Marchal, 1861), V, p. 391.

${ }^{67}$ Ibíd., cap. $1^{\circ}$, art. $1, \$ 1$, núm. 5, en Euvres, V, p. 391-392. 
De acuerdo con esto, pues, el "nantissement" admite ser constituido sobre muebles e inmuebles. En este último caso, el inmueble es entregado al acreedor para que perciba sus frutos y los impute a pago de la deuda. Aunque Pothier no da nombre a esta figura, se está refiriendo a la que los romanos denominaban "anticresis". De esta manera, podemos decir que, para Pothier, la anticresis es una especie de "nantissement".

Ahora bien, fue este esquema el que siguieron los codificadores franceses cuando, bajo el concepto de "nantissement", incluyeron uno sobre muebles, al que denominaron "gage", y otro sobre inmuebles, al que llamaron "antichrèse", trasladando a la primera el nombre que Pothier también había impuesto al género ("s'appelle nantissement; elle s'appelle aussi gage").

b) Pero los codificadores también tuvieron a la vista el Traité de l'hypothèque. La parte principal de este libro está dedicada a lo que indica su título; pero en él Pothier también trató del "nantissement" y de la "antichrèse".

Leemos ahí:

"L'hypothèque, ou droit de gage, est le droit qu'un créancier a dans la chose d'autrui, qui consiste à pouvoir la faire vendre, pour, sur le prix, être payé de sa créance" 68 .
"La hipoteca, o derecho de prenda, es el dereho que un acreedor tiene en la cosa de otro, que consiste en poder hacerla vender para ser pagado de su crédito sobre el precio".

Pothier, pues, conforme con el Derecho romano, identifica hipoteca y derecho de prenda. Añade enseguida:

"Il y a deux espèces d'hypothèques: celle qu on appelle nantissement, pignus, et celle qu'on appelle proprement hypothèque. Le nantissement est l'espèce d'hypothèque qui se contracte par la tradition qui est faite de la chose au créancier et qui lui donne droit de la retenir pour sûreté de sa créance jusqu au parfait paiement et même de la faire vendre à défaut de paiement. L'hypothèque proprement dite est celle qui se contracte sans tradition" ${ }^{6}$.
"Hay dos especies de hipoteca: aquella que se llama 'nantissement', pignus, y aquella que se llama propiamente hipoteca. El 'nantissement' es la especie de hipoteca que se contrae por la entrega que se hace de la cosa al acreedor y que le da derecho de retenerla para seguridad de su crédito hasta el pago completo y también de hacerla vender en defecto de pago. La hipoteca propiamente dicha es aquella que se contrae sin entrega".

${ }^{68}$ Pothier, Robert-Joseph, Traité de l'hypothèque, article préliminaire, núm. 1, en Euvres, cit., IX, p. 423.

${ }^{69}$ Ibíd., núm. 2. 
Siempre en conformidad con el Derecho romano, Pothier distingue dentro de la hipoteca (o prenda) el "nantissement", que se contrae por la entrega de la cosa en garantía al acreedor; y la "hypothèque proprement dite", que se contrae sin tal entrega. Todavía en el interior del mismo tratado, en el capítulo dedicado al "nantissement", Pothier insiste en estos conceptos:

"Le nantissement est une espèce de gage qui se contracte par la tradition qui est faite au créancier de la chose qu'on lui engage. [...]. En cela il differe de l'hypothèque proprement dite qui se contracte par la seule convention sans faire passer la possession de la chose au créancier" ${ }^{70}$.
“El 'nantissement' es una especie de prenda que se contrae por la entrega que se hace de la cosa que se le pignora. [...]. En esto difiere de la hipoteca propiamente dicha, que se contrae por la sola convención sin hacer pasar la posesión de la cosa al acreedor”

Pero ahora añade un matiz positivo a la hipoteca: antes había dicho que ella se contrae "sin entrega"; y ahora aclara que se contrae "por la sóla convención" (sin hacer pasar la posesión de la cosa al acreedor).

Pothier estudia la anticresis dentro del mismo Traité de l'hypothèque por las afinades que ofrece: "Ce droit est un droit dans la chose aussi bien que le droit d'hypotheque" 11 . Pero no se identifica estructuralmente con el "nantissement". Se le parece en cuanto la anticresis exige que la cosa sea entregada al acreedor, quien, pues, la puede retener hasta pagarse de su deuda con los frutos de aquélla; pero se diferencia en cuanto el acreedor no puede vender la cosa dada en anticresis. Tema distinto es que puedan concurrir la anticresis y la hipoteca, si un deudor hipotecó un bien y acordó con su acreedor que lo tuviera para aprovecharse de sus frutos y pagarse con ellos. Pero es perfectamente posible que se separen y haya hipoteca sin anticresis y anticresis sin hipoteca.

c) Se observará que en estos textos Pothier no se dice palabra alguna acerca del tipo de cosas sobre que recaen el "nantissement" y la "hypothèque proprement dite". Pero, en realidad, había sido en el comienzo mismo del Traité de l'hipothèque que él se había explayado al respecto:

${ }^{70}$ Ibid., cap. $4^{\mathrm{o}}$ : ”Du nantissement”, art. 1º $\$$ I, núm. 208, en Euvres, cit., IX, p. 481.

${ }^{71}$ Ibíd., cap. 50: "De l' antichrèse et du contrat pignoratif ", núm. 231, en $E$ uvres cit., IX, p. 488: "Este derecho es un derecho en la cosa, igual que el derecho de hipoteca". 
“34. Suivant le Droit romain toutes les choses qui sont dans le commerce, soit meubles, soit immeubles, soit corporelles, soit incorporelles, sont susceptibles d'hypothèque. 35. Notre Droit differe en cela du Droit romain. Il n'y a que les immeubles qui soient susceptibles d'une véritable hypothèque; les meubles ou n'en sont pas susceptibles, ou ne le sont que d'une hypothèque imparfaite. Dans les coutumes de Paris et d'Orléans les meubles ne sont point susceptibles d'hypothèque et les créanciers hypothécaires ne sont payés sur le prix des meubles de leurs débiteurs, que concurremment avec les simples chirographaires, au sol la livre de leurs créances. Dans quelques autres, telle que celle de Normandie, les meubles sont susceptibles d'hypothèque et les créanciers hypothécaires sont colloqués par ordre d'hypothèque sur le prix des meubles de leurs débiteurs comme sur le prix des immeubles. 36. Mais cette hypothèque des meubles reçue dans ces coutumes n'est qu'une hypothèque imparfaite qui ne dure que tant que les meubles sont en la possession du débiteur qui les a hypothéqués et qui s'éteint lorsqu ils ont été aliènes et ont passé en la main d'un autre suivant celle maxime générale du Droit français 'Meubles n'ont de suite par hypothèque'. Ce qui a été introduit pour la sûreté et facilité du commerce"72.
“34. Según el Derecho romano, todas las cosas que están en el comercio, sean muebles, sean inmuebles, sean corporales, sean incorporales, son susceptibles de hipoteca. 35. En esto nuestro Derecho difiere del Derecho romano. No son más que los inmuebles los susceptibles de una verdadera hipoteca; los muebles, o no son susceptibles de hipoteca, o lo son no más que de una manera imperfecta. En las costumbres de París y de Orleans, los muebles no son en ningún caso susceptibles de hipoteca y los acreedores hipotecarios no son pagados sobre el precio de los muebles de sus deudores sino que en concurrencia con los simples quirografarios en proporción a sus créditos. En algunas otras, como en aquella de Normandía, los muebles son susceptibles de hipoteca y los acreedores hipotecarios van colocados según el orden de sus hipotecas sobre el precio de los muebles de sus deudores como sobre el precio de los inmuebles. 36 . Pero esta hipoteca de muebles recibida en estas costumbres no es más que una hipoteca imperfecta, que dura en tanto que los muebles estén en la posesión del deudor que los ha hipotecado y que se extingue cuando ellos han sido enajenados o han pasado a manos de otro, según la máxima general del Derecho francés: 'Los muebles no tienen persecución por hipoteca'. Lo cual ha sido introducido para la seguridad y facilidad del comercio"

Por ello es que después, tratando ahora del "nantissement", reitera:

${ }^{72}$ Ibíd., cap. $1^{\mathrm{o}}$ : "De ci que concerne la création de l'hypothèque", art. $3^{\mathrm{o}}$, sec. $2^{\mathrm{a}}$, $\$ 1$, núms. 34-36, en Cuvres, cit., IX, pp. 434-435. 
"Le nantissement differe encore de l'hypothèque proprement dite touchant les choses qui en sont susceptibles; car au lieu qu'il n'y a que les immeubles qui soient susceptibles de l'hypothèque proprement dite dans la plupart de nos coutumes au contraire ce sont principalement les meubles qui sont susceptibles du nantissement"73.
“El 'nantissement' difiere aún de la hipoteca propiamente dicha en lo tocante a las cosas que son susceptibles de él; porque, en lugar de que no sean sino los inmuebles los susceptibles de hipoteca propiamente dicha, en la mayoría de nuestras costumbres, por el contrario, son principalmente los muebles los susceptibles de 'nantissement"”.

En el primer texto, pues, Pothier deja constancia que en el Derecho romano, tanto las cosas muebles como las inmuebles son objeto de hipoteca. Pero enseguida añade haber una diferencia al respecto entre aquel Derecho y el francés. Por "Droit français" Pothier entiende el de las "coutumes". Según él, objetos de una verdadera hipoteca son sólo los inmuebles. Por lo que atañe a los muebles, o no son susceptibles de hipoteca, como en las costumbres de Paris y de Orléans ${ }^{74}$, o sólo lo son de una hipoteca imperfecta, como en la costumbre de Normandía. La imperfección de esta hipoteca mobiliaria de la costumbre normanda radica en que ella persiste tan sólo mientras el mueble esté en poder del deudor que la constituyó, pero se extingue desde que éste lo enajenó o cuando pasó a manos de terceros por cualquier otra causa. Al efecto, cita una "máxima general del Derecho francés": "Meubles n'ont de suite par hypothèque", porque en efecto, una vez pasado a manos de terceros el mueble hipotecado, el acreedor no los puede perseguir, que es lo mismo que decir que la hipoteca se extingue. Pero mientras subsista la hipoteca, el acreedor goza de preferencia frente a los demás acreedores. En otras costumbres, en cambio, como en las de Paris y Orléans, la hipoteca de muebles simplemente no produce efecto: el acreedor hipotecario no goza de preferencia alguna frente a los demás acreedores y su rango es el de un quirografario con quienes, pues, concurre. Por lo que expresa al final Pothier, debemos agregar que, con mayor razón, tampoco en la costumbre de Paris y Orléans la prenda mobiliaria

${ }^{73}$ Ibíd., cap. 40: ”Du nantissement", art. 1º, \$ II, núm. 210, en Euvres, cit., IX, p. 482.

${ }^{74}$ Lo confirma el mismo autor en su comentario a la coutume d'Orléans. Véase: Pothier, R.-J., Coutumes des duché bailliage et prévôté d'Orléans et ressort de iceux, cap. $1^{\circ}$, sec. $2^{\text {a }}, \$ 1$, núm. 21 , en CEuvres, I, p. 644-645: “Tous les immeubles qui sont dans le commerce sont susceptibles d'hypothèque; non seulement les héritages mais pareillement les droits réels même les rentes constituées et les offices. A l'égard des meubles quoiqu'ils soient susceptibles des trois premières espèces d'hypothèques mentionnées supra $n^{o} .2$ ils ne sont pas, dans notre coutume, susceptibles de l'hypothèque proprement dite dont nous traitons ici". 
daba persecución, según la misma máxima general del Derecho francés antes citada.

Estos textos nos ofrecen la clave de lo ocurrido a la hipoteca mobiliaria en el Derecho de las costumbres francesas. Ellas habían modificado al antiguo Derecho romano que la aceptaban ampliamente; y la habían reducido a una garantía muy poco o nada eficaz. En un medio así, debemos suponer que nadie habría de recurrir a ella.

5. Las interesantes noticias que nos transmite Pothier están muy bien corroboradas por otros autores.

a) $\mathrm{Al}$ efecto, podemos recurrir al Dictionnaire de Droit et pratique (1740), de Claude-Joseph Ferrière (1680?-1748?). Bajo la voz "gage", en donde leemos:

"Gage, est un effet que l'on remet entre les mains de quelqu'un pour sûreté du payement d'une somme, ou de l'exécution de quelqu'autre convention, à l'effet de le retenir jusqu'a ce que la dette soit payée ou la convention exécutée. Le terme de gage se prend aussi quelquefois pour le contrat par lequel on donne l'effet en gage. On appelle simple gage, le meuble qui est donné comme pour nantissement et sûreté de la dette au créancier jusqu'à parfait payement Se on appelle hypothèque, la convention par laquelle on engage et obligue à la dette un immeuble; en sorte que, quoiqu'on dise vulgairement de l'hypothèque comme du simple gage, ceci est mon gage. Cependant donner en gage s'entend des choses mobiliaires et hypothéquer des choses immobiliaires. Gages et hypothèques différent dont principalement, en ce que le gage ne se forme que par la tradition d'un chose mobiliaire et l'hypothèque se constitue sans tradition sur un immeuble qui dévient obligé et hypothéqué au créancier pour sûreté de sa dette, et demeure toutefois en la possession du débiteur"75.
"La prenda es un efecto que se entrega en manos de alguien para seguridad del pago de una suma o de la ejecución de cualquier otra convención, a efecto de retener hasta que la deuda sea pagada sea pagada o la convención ejecutada. El término 'prenda a veces también se toma por el contrato por el cual se da el efecto en prenda. Se llama prenda simple el mueble que es dado como por 'nantissement' y seguridad de la deuda al acreedor hasta el pago completo. Se llama hipoteca la convención por la cual se pignora y obliga un inmueble a la deuda; de suerte que, si bien se dice vulgarmente de la hipoteca como de la prend simple, esta es mi prenda. Sin embargo, dar en prenda se entiende de las cosas muebles e hipotecar, de las cosas inmuebles. Prendas e hipotecas difieren, pues, principalmente en que la prenda no se forma sino que por la entrega de una cosa mueble y la hipoteca se constituye sin entrega sobre un inmueble que deviene en obligado e hipotecado al acreedor para seguridad de su deuda y permanece siempre en posesión del deudor". 
Ferrière, después de definir en general el "gage", distingue un "simple gage" recayente en muebles y que se perfecciona por la entrega del mismo; y la "hypothèque", que tiene por objeto a los inmuebles y no exige entrega de estos.

Enseguida se ocupa en explicar que la distinción, tal cual quedó antes explicada, no es romana sino francesa:

"Mais quoique le gage et l'hypotheque soient souvent pris dans les Loix Romaines pour la même chose et dans la même signification ils different néanmoins en plusieurs choses même suivant le Droit Romain. [...]. Dans notre usage nous appellons gage le contrat par lequel celui qui emprunte de l'argent met entre les mains de son créancier un effet mobilier pour sûreté de sa dette et nous donnons le nom hypothèque à l'obligation par laquelle les immeubles du débiteur sont affectés et hypothéqués au créancier pour sûreté de sa dette en sorte que ces deux choses ne se prennent pas chez nous pour la même, \& que ces deux termes ont différentes significations d'autant plus qu'en France les meubles n'ont point de suite par hypothèque et que les inmeubles ne se donnent point en gage comme nous le dirons dans la suite" ${ }^{36}$.
"Mas, aunque la prenda y la hipoteca a menudo sean tomadas como una misma cosa y en la misma significación en las leyes romanas, ellas, sin embargo, difieren en varios puntos, incluso en las leyes romana. [...]. En nuestra usanza, llamamos prenda al contrato por el cual aquel que toma dinero en préstamo pone en manos de su acreedor un efecto mobiliario para seguridad de su deuda; y damos el nombre de hipoteca a la obligación por la cual los inmuebles del deudor son afectados e hipotecados al acreedor para seguridad de su deuda, de suerte que estas dos cosas no se toman entre nosotros como la misma y que estos dos términos tienen diferente significación, tanto más que en Francia los muebles absolutamente no tienen persecución por hipoteca y que los inmuebles no se dan en ningún caso en prenda, como lo diremos en lo que sigue".

En Francia, pues, no hay hipoteca de muebles ni prenda de inmuebles. A continuación, Ferrière da la razón del régimen francés:

"Chez les Romains, l'hypothèque se constituoit par la seule convention du débiteur, qui obligeoit ses biens pour la sûreté de la dette; et l'hypothèque se pouvoit constituer tant sur des effets
"Entre los romanos, la hipoteca se constituía por la sola convención del deudor que obligaba sus bienes para seguridad de la deuda; y la hipoteca se podía constituir tanto sobre efectos

des termes de Droit, d'ordonnance, de coutumes et de pratique avec les juridictions de France (nouvelle édition, Paris, Brunet, 1769), s.v. "Gage”, p. 630.

${ }^{76}$ Ibíd., s.v. "Hypothèque", p. 692. 
mobiliers, que sur des immeubles. Mais en France l'hypothèque ne se constitue que sur des immeubles, et non point sur les meubles et c'est principalement en cela que l'hypothèque differe du gage parmi nous. [...]./ La raison pour laquelle les effets mobiliers ne sont point en France susceptibles d'hypothèque, est qu'il y auroit trop d'inconvéniens d'assujettir au droit de suite les meubles qui sont si sujets à changer de main, qu'ils peuvent, comme dit $\mathrm{M}$. Charles Dumoulin 'una hora transire per centum manus'. Nous ne suivons pas encore la disposition du Droit Romain en ce que suivant elle, la seule convention des Parties étoit suffisante pour constituer une hypothèque. Mais la seule convention des Parties n'est pas capable en France de constituer hypothèque; il faut pour cet effet le ministère des personnes publiques, sçavoir des Juges, ou des Notaires" 77 . mobiliarios, como sobre inmuebles. Pero en Francia la hipoteca no se constituye más que sobre inmuebles, y absolutamente no sobre muebles y es principalmente en esto que la hipoteca difiere de la prenda entre nosotros. [...]./ La razón por la cual los efectos mobiliarios no son en absoluto susceptibles de hipoteca en Francia, es que habría demasiados inconvenientes en someter al derecho de persecución los muebles, que están tan sujetos a cambiar de manos, que ellos pueden, como dice el señor Charles Dumoulin, 'transitar por cien manos en una hora'. Nosotros tampoco seguimos la disposición del Derecho romano en aquello en que, según ella, las sola convención de las partes era suficiente para constituir una hipoteca. Pero la sola convención de las partes no es capaz de constituir hipotecas en Francia; para este efecto es necesario el ministerio de personas públicas, a saber, de jueces o de notarios".

Los muebles - dice- están sujetos a cambiar rápidamente de manos, y al efecto cita un aserto pertinente de Dumoulin. Va implícito que ello puede perjudicar al acreedor en la función garantizadora que se espera de la hipoteca, si ésta se hace recaer sobre muebles que permanecen en poder del deudor. Se añade lo que había dicho en el texto antes citado, en orden a que en Francia “les meubles n'ont point de suite par hypothèque”.

b) Algo nada diferente narra Jean Domat (1625-1696):

"Comme la nature de l'hypothèque est d'affecter les biens pour la sûreté des engagemens et que par exemple, le créancier d'une somme d'argent assure son payement sur le droit de suivre par tout la chose qui lui est hypothéquée, il est nécessaire de remarquer une différence importante entre notre usage $\&$ le Droit Romain, en ce qui regarde l'assurance sur les
"Como la naturaleza de la hipoteca es afectar los bienes para seguridad de los compromisos y que, por ejemplo, el acreedor de una suma de dinero asegure su pago con el derecho de perseguir por todas partes la cosa que le es hipotecada, es necesario remarcar una diferencia importante entre nuestra usanza y el Derecho romano, en lo que mira a la seguridad sobre los muebles y efectos

${ }^{77}$ Ibíd., pp. 692-693. 
meubles \& effets mobiliaires des débiteurs. Dans le Droit Romain l'hypothèque avoit même effet sur les meubles que sur les immeubles avec ce droit de suite. Mais les inconvéniens d'assujettir à ce droit de suite les meubles si sujets à changer de main, ont fait établir autre jurisprudence dans ce Royaume. El c'est notre règle que l'hypothèque sur le meuble ne dure que tandis qu'il demeure en la puissance de celui qui est obligé, ou que celui qui l'a pour sûreté s'en trouve saisi. Mais si le débiteur le fait passer en d'autres mains, ou par une aliénation ou le donnant en gage, on ne peut plus le suivre. C'est cette règle qu'on exprime par ces mots, que 'Meuble n'a point de suite par hypothèque'. / L'usage est donc en France à l'égard des meubles, que les créanciers y exercent leur droit en deux manières. L'une lorsque le meuble est en la puissance du créancier qui en est saisi \& qui le tient en gage. Et l'autre lorsque le meuble est en la puissance du débiteur ou d'autres personnes qui l'ont en son nom, comme un dépositaire ou celui qui l'a emprunté ou un autre créancier qui aurait en gage un meuble dont la valeur excederoit celle de la dette Au premier cas, le créancier peut faire vendre le meuble, si le débiteur y consent, ou à son refus par autorité du juge, pour être payé sur le prix qu s'en tirera, par préférence à tous autres créanciers même antérieurs, mais non au préjudice du créancier qui auroit un privilège sure ce même gage. Dans le second cas le créancier peut saisir \& faire vendre le meuble de son débiteur $s$ 'il a une hypothèque fur les biens ou une permission du juge pour saisir" ${ }^{78}$. mobiliarios de los deudores. En el Derecho romano la hipoteca tenía el mismo efecto sobre los muebles y sobre los inmuebles, con este derecho de persecución. Pero los inconvenientes de someter a este derecho de persecución los muebles, tan sujetos a cambiar de mano, han hecho establecer otra jurisprudencia en este Reino. Es regla nuestra que la hipoteca sobre un mueble no dure tanto más que mientras él permanezca en el poder de aquel que está obligado, o mientras aquel que lo tiene en seguridad se encuentre posesionado en él. Pero si el deudor lo hace pasar a otras manos, por una enajenación o dándolo en prenda, ya no se lo puede perseguir. Es la regla que se expresa con estas palabras: 'Mueble no tiene absolutamente persecución por hipoteca'./ En relación con los muebles, la usanza es, pues, en Francia que los acreedores ejerzan su derecho de dos maneras. Uno, cuando el mueble está en el poder del acreedor que se ha posesionado de él, y lo tiene en prenda. El otro es cuando el mueble está en poder del deudor o de otra persona que lo tiene a su nombre, como un depositario o aquel que lo ha recibido en comodato $\mathrm{u}$ otro acreedor que tuviera en prenda un mueble cuyo valor excediera a aquel de la deuda. En el primer caso, el acreedor puede hacer vender el mueble, si el deudor lo consiente o, en caso de rehusarse, por autoridad del juez, para ser pagado sobre el precio que se obtendrá, con preferencia a todos los otros acreedores, incluso anteriores, pero sin perjuicio del acreedor que tuviera un privilegio seguro sobre esa misma prenda. En el segundo caso, el acreedor puede asir y hacer vender el mueble de su deudor si tiene una hipoteca sobre los bienes o un permiso del juez para asir"

${ }^{78}$ Domat, Jean, Les lois civiles dans leur ordre naturel, lib. III, tít. $1^{\mathrm{o}}$, sec. $1^{\mathrm{a}}$, núm. 
Domat contrapone el régimen romano y el francés. En el Derecho romano, la hipoteca recae indistintamente sobre muebles e inmuebles y en ambos casos con derecho de persecución contra terceros. Pero los inconvenientes de sujetar muebles a hipotecas, que cambian constantemente de manos, hizo mudar en Francia el principio romano. Ahí la hipoteca sobre muebles no persiste más que en tanto el objeto permanezca en las manos del que la constituyó o del acreedor (si después de acordada la hipoteca, por cualquier causa tomó posesión de ese objeto). Pero cuando pasa a manos de terceros, ya no se lo puede perseguir. Al efecto cita la consabida regla: "Meuble n'a point de suite par hypothèque".

El abogado del Parlamento de Rouen, Henri Basnage de Franquenay (1615-1695), autor de un Traité des hypothéques (1681) -en donde destina un capítulo completo al estudio "De l'hypothèques sur les meubles"-, había explicado las razones de la regla así:

"C'est une maxime certaine par le Droit François que 'meuble n'à point de suite par hypothèque', c'est à dire que le créancier ne peut saisir les meubles en d'autres mains qu'en celles de son débiteur; ce qui est fondé sur ces trois raisons. La première que les meubles n'ont pas une subsistance perpétuelle \& certaine comme les immeubles, \& par conséquent ils n'ont pas une si grande aptitude à recevoir le caractère d'hypothèque en vertu d'une simple convention. La seconde, que le créancier ayant pu se faire nantir du meuble qu'on luy engageoit, il se doit imputer s'il n'a pas pris son assurance. Et la troisième que si les meubles avoient suite par hypothèque l'on rendroit le commerce extrêmement incommode, ou pour mieux dire on l'aboliroit tout à fait, parce qu'un acheteur ne seroit jamais en sûreté. Ainsi l'hypothèque sur les meubles est imparfaite, comme elle que sur les offices, puis qu'elle n'a point le principal effet de
"Para el Derecho francés es una máxima cierta que 'mueble no tiene absolutamente persecución por hipoteca', es decir, que el acreedor no puede coger los muebles en otras manos que no sean aquellas de su deudor; lo cual se funda en tres razones. La primera es que los muebles no tienen una subsistencia perpetua y cierta como los inmuebles, y, por consiguiente, no tienen una tan gran aptitud para recibir el carácter de la hipoteca en virtud de una simple convención. La segunda es que el acreedor, habiendo podido hacerse tenedor del mueble que le ha sido pignorado, debe imputar a sí mismo si él no ha tomado su seguridad. Y la tercera es que si los muebles tuvieran persecución por hipoteca el comercio se haría extremadamente incómodo o, por mejor decir, se lo aboliría completamente, porque un comprador jamás estaría en seguridad. Así, la hipoteca sobre los muebles es imperfecta, como aquella sobre los oficios, porque

1, en Domat, Jean, les lois civiles dans leur ordre naturel, Les lois civiles dans leur ordre naturel, le Droit public et "legum delectus" (Paris, chez Th. de Hansy, 1735), I, pp. 191-192. 
l'hypothèque, qu'est la suite. Il faut néanmoins remarquer qu'en Normandie cette hypothèque a plus d'effet qu'elle n'en dans la Coutume de Paris $\&$ dans plusieurs autres, en ce que les créanciers conservent leur droit de priorité nonobstant la saisie faite des meubles de leur obligé par un créancier postérieur" ${ }^{\prime 9}$. en ningún caso tiene el principal efecto de la hipoteca, que es la persecución. Sin embargo, es necesario remarcar que en Normandía esta hipoteca tiene más efecto que en aquélla de la costumbre de Paris y de varios otros lugares, en cuanto los acreedores conservan su derecho de prioridad, no obstante el posesionamiento de los muebles que le están obligados, hecho por un acreedor posterior”.

Basnage ofrece, pues, tres razones. La segunda es de dudosa consistencia: que haya estado en las manos del acreedor haber exigido la entrega de los muebles pignorados y no haberlo hecho, eso hace que deba imputar a sí mismo la imposibilidad de no poderlos perseguir después, envuelve una petición de principios. La primera razón, de que los muebles no tengan una subsistencia perpetua y cierta, como sí la tienen los inmuebles, es más poderosa. Lo mismo que la tercera, en orden a que si hubiera persecución de muebles, el comercio de éstos se haría desventajoso, porque ningún comprador podría tener la seguridad de haber adquirido algo que nadie le pueda reclamar. Pero que eso mismo, más que estorbar, haya de abolir el comercio, es una evidente exageración.

Se observará que Pothier había dado una razón muy general para justificar la introducción de la regla consuetudinaria: "pour la sûreté et facilité $d u$ commerce" ${ }^{" 0}$, y podemos considerar esta afirmación como una formulación sintética de la primera y tercera razones de Basnage. Por su parte, Ferrière se había explayado un tanto más:

"La raison pour laquelle les effets mobiliers ne sont point en France susceptibles d'hypothèque, est qu'il $y$ auroit trop d'inconvéniens d'assujettir au droit de suite les meubles qui sont si sujets à changer de main, qu'ils peuvent, comme dit M. Charles Dumoulin 'una hora transire per centum manus"" 1 .
"La razón por la cual los efectos mobiliarios no son en absoluto susceptibles de hipoteca en Francia, es que habría demasiados inconvenientes en someter al derecho de persecución los muebles, que están tan sujetos a cambiar de manos, que ellos pueden, como dice el señor Charles Dumoulin, 'transitar por cien manos en una hora”.

${ }^{79}$ Basnage, Henri, Traité des hypothèques divisé en deux parties, $1^{\text {a }}$ parte, cap. $9^{\circ}$ (2a edición, Rouen, Chez Jean Lucas, 1687), p. 67.

${ }^{80}$ Véase la nota 72.

${ }^{81}$ Véase la nota 77. 
Esto corresponde a la primera razón de Basnage. Por otro lado, esta última razón será repetida por Pufendorf y Wolf, como antes observamos ${ }^{82}$.

c) Con la anterior revisión es suficiente para nuestros fines. Una más amplia confirmará lo dicho por los textos que hasta ahora hemos presentado. Tan sólo nos resta por hacer notar que la máxima del "Droit Français": "Meuble n'a point de suite par hypothèque", reiteradamente invocada por los autores antes vistos, también la encontramos, aunque aisladamente expresada, en las Institutions coutumières (1607) de Antoine Loysel (15361617): “Meubles n'ont point de suite par hypothèque quand ils sont hors de la possession du detteur" ${ }^{83}$. Ahora bien, ella está documentada desde antes, al menos para el siglo XVI ${ }^{84}$. Pero tuvo su antecedente en una máxima más general que tan sólo rezaba "Meubles n'ont pas de suite”, la cual, a su vez, se encuentra documentada desde el siglo XIV ${ }^{85}$. El sentido de esta última es discutido, en orden a si iba dirigida a impedir la reivindicación de inmuebles, como piensan casi todo los autores ${ }^{86}$, o más bien a paralizar las acciones personales o crediticias contra un deudor ${ }^{87}$. Fuera como haya sido, es claro, sin embargo, que la regla, ya limitada a la hipoteca, atañe a la acción hipotecaria, que es in rem. En el siglo XVIII, la idea de una inmunidad de los muebles a toda persecución decanta en esta regla: "En matière de meubles, possession vaut titre" (después recogida en el Code Civi ${ }^{88}$ ), que parece haber sido formulada la vez primera por Francois Bourjon $(\dagger 1751)$, en su obra Le droit commun de la France (1743), en quien, por lo demás, aparece como fundamento tanto de la regla más amplia: "Meubles n'ont

${ }^{82}$ Véase, más arriba, en este mismo cap. $4^{\circ}$, su número 3 letras a) y b).

${ }^{83}$ Loysel, Antoine, Institutes coutumières, lib. III, tít. 7o: "Du gage et hypothèques", aforismo $5^{\circ}$ (núm. 487) (2a edición por Dupin, M. - Laboulaye, E., Paris, Videcoq - Durand, 1846), I, p. 428: "Los muebles no tienen en absoluto persecución por hipoteca cuando están fuera de la posesión del deudor".

${ }^{84}$ Véase la literatura citada en las notas 86 y 87.

${ }^{85}$ Tal es la versión francesa de la máxima: "mobilia non habent sequelam”, que hasta la época de la Recepción del Derecho romano se mantuvo vigente en muchos países de origen germánico.Sobre ella, véase: VAN ApELDOORn, L. J., Mobilia non haben sequelam, en Tijdschrift voor Rechsgeschiedenis/ Revue de Histoire de Droit 11 (1932) 2, pp. 133-186.

${ }^{86}$ Sobre la base de Jobbé-Duval, Émile, Étude historique sur la revendication des meubles en Droit Français (Paris, Larosse, 1880). Otra literatura en Patault, AnneMarie, Introduction historique au droit des biens (Paris, Presses Universitaires de France, 1989), núm. 256, p. 300; y ésta misma, ibíd., pp. 292-301.

${ }^{87}$ Que es la tesis de Pos, A. G., Meubles n'ont pas de suite, en Tijdschrift voor Rechtgeschiedenis/ Revue d'Histoire de Droit, 41 (1941) 1, pp. 45-58.

${ }^{88}$ CCFr., art. 2279 inciso 10: "En fait de meubles, possession vaut titre" ("En hecho [sc. en materia] de muebles, la posesión vale como título”). 
pas de suite", como de aquella más especial: "Meubles n'ont pas de suite par hypothéque", como se ve a continuación:

"1. En matière de meubles, la possession vaut titre de propriété; la sûreté du commerce l'esige ainsi; la base de cette maxime, est qu'on ne possède ordinairement que les meubles dont on est propriétaire; ainsi la possession doit donc quant à ce, décider; c'est le meilleur guide, et quel autre pouvoiton prendre sans tomber dans la confusion?/ De-la s'ensuit que dans la thèse générale, les meubles ne sont sujets à suite $[\ldots.] . / 3$. Hors les cas singuliers, [...], les meubles et effets mobiliers ne sont sujets à suite para hypothèque; leur nature et la possession quant à eux décisive, les affranchissent de ce droit" 89 .
"En materia de muebles, la posesión vale como título de propiedad; la seguridad del comercio así lo exige; la base de esta máxima es que ordinariamente no se posee más que los muebles de los cuales se es propietario; así, pues, la posesión debe decidir en cuanto a esto; es la mejor guía, ¿y a cuál otra se podría recurrir sin caer en la confusión? De ahí se sigue que, en tesis general, los muebles no están sujetos a persecusión [...]./ 3. Fuera de los casos singulares, [...], los muebles y efectos mobiliarios no están sujetos a persecusión por hipoteca; su naturaleza y la posesión, en cuanto a ellos decisiva, los libera de este derecho".

6. La última síntesis de todo lo anterior, pues, es que la división entre una prenda sólo sobre muebles, con desplazamiento del bien pignorado al acreedor, y una hipoteca nada más que sobre inmuebles sin desplazamiento de estos al acreedor, y la imposibilidad o imperfección de una hipoteca mobiliaria o prenda de muebles sin su desplazamiento, fueron introducidas en Francia por las coutumes en contra del Derecho romano.

\section{LA EVOLUCIÓN DEL DERECHO PRENDARIO EN LOS SIGLOS XIX Y XX}

1. Ahora podemos retornar al punto de partida, vale decir, al Derecho prendario codificado, en donde, como se recordará, primó el principio "coutumier", que hacía ineficaz una hipoteca mobiliaria o prenda sobre muebles con desplazamiento; lo cual condujo a una rígida separación de la prenda, sea sólo de muebles, sea de muebles e inmuebles, y la hipoteca, única y exclusivamente sobre inmuebles. El Code Civil dejó firmemente establecida la reducción de la prenda a los muebles; pero se sintió impelido a recoger el antiguo principio del "Droit Français (coutumier)", que tantas veces hemos visto comparecer, en su artículo 2119: "Les meubles n'ont pas de

${ }^{89}$ Bourjon, François, Le droit commun de la France et la coutume de Paris réduits en principes, lib. II, tít. $1^{\circ}$, cap. $6^{\circ}$, sec. $1^{\mathrm{a}}$, núms. 1 y 3 (Paris, Grangé - Cellot, 1779), I, p. 145. 
suite par hypothèque". Esta norma es completamente inútil en el código: su artículo 2072 dice que el "nantissement" de una cosa mueble se denomina "gage", en el entendido que él exige entregar el objeto al acreedor (artículo 2071); y su artículo 2114 expresa que la hipoteca es un derecho real que recae sobre inmuebles. En fin, del artículo 2129 se deduce que el Code no acepta la hipoteca universal de bienes. Está claro, pues, que no hay hipoteca sobre muebles. Así que insistir en que los muebles no admiten persecución por hipoteca es decir algo que a nadie se le podría ocurrir contradecir, precisamente porque la hipoteca de muebles no existe para el código. El artículo 2119 fue, pues, un innecesario homenaje al "Droit coutumier"; pero muestra la preponderancia que él tuvo en esta materia.

2. Muy prontamente, los hechos económicos se encargaron de demostrar que los codificadores franceses cometieron un error histórico de grandes proporciones cuando otorgaron su preferencia al "Droit coutumier" por sobre el Derecho romano. Esos hechos hicieron ver las ventajas que ofrece la hipoteca mobiliaria ${ }^{90}$ en una sociedad crecientemente industrializada en los ámbitos fabril y agrícola.

Frecuentemente acaece al emprendedor económico, que necesita un crédito, no tener otro bien que ofrecer en garantía a sus eventuales prestamistas sino aquel que ha de constituir la base de su emprendimiento, por ejemplo, las herramientas y los equipos que deben ser usados para la operación, o las mercaderías que surten su negocio comercial, o las maquinarias y materias primas de su industria fabril, etcétera. De afectar tales bienes con desplazamiento en garantía del crédito que necesita, el emprendedor dispone ahora de capital dinerario, pero se priva de la base material para la operación de su empresa; que si desea conservar, ahora no obtiene el capital que busca; así que cae presa de un círculo vicioso. Él se soluciona cuando le es permitido constituir la garantía sobre los bienes muebles básicos de su empresa agrícola o fabril, sin necesidad de desplazar su tenencia al acreedor, de modo de producirse una postergación del desplazamiento hasta el momento de la mora. Tal se hace posible por el carácter real conferido a la actio pigneraticia, aun en contra del dueño del objeto pignorado o constituyente de la garantía, para perseguirlo y preparar su realización o venta ejecutiva, en función de satisfacer el crédito impago. Ni más ni menos, estas necesidades fueron la que en la antigua

${ }^{90}$ Planiol, Marcel - Ripert, Georges, Traité pratique de Droit civil Français (2a edición, Paris, LGDJ., 1927), XII: "Sûretés réeles", $1^{\text {a }}$ parte, p. 251, protestan contra la denominación de "gages sans dépossession", porque las así llamadas "sont des véritables hypothèques mobilières". 
Roma habían incitado la creación del pignus conventum sobre muebles e inmuebles, que el Code Civil desconoció.

Pero tales necesidades insatisfechas terminaron por sensibilizar la conciencia de los legisladores y por hacer proveer a la existencia de la prenda mobiliaria sin desplazamiento o hipoteca mobiliaria. Con algunas ventajas añadidas: i) de hacerla posible sobre cosas futuras y sobre universalidades de hecho, lo que no es procedente en la prenda con desplazamiento, porque las cosas futuras y las universalidades no pueden ser entregadas; ii) la de hacerla posible sobre derechos personales que no constan en un título-valor o de crédito que pueda ser entregado cuando es al portador o endosado si es a la orden; y iii) la de hacerla posible sobre derechos reales muebles.

La contrapartida forzosa fue mudar la naturaleza real del contrato, porque la prenda de muebles sin desplazamiento debió empezar a ser solemne, e, idealmente al menos, a exigir una inscripción, igual que la hipoteca de inmuebles.

2. Fue desde la segunda mitad del siglo XIX que se abrió paso a la idea de las hipotecas mobiliarias o prendas sobre muebles sin su desplazamiento posesorio. Pero esta idea fue constantemente presentada como una excepción o especialidad introducida en el Derecho prendario común y general, que exigía la entrega de los muebles pignorados al acreedor; y por eso nunca, hasta fines del siglo XX, se adoptó una reforma general que permitiera la constitución de prendas de muebles sin su desplazamiento posesorio, también como regla general, vale decir, sobre toda clase de muebles y para toda clase de deudas, de modo que fueran las partes las que, al pignorar un mueble, escogieran libremente entre su entrega al acreedor o su retención por el constituyente. Entre otros tantos ejemplos, los más caracterizados fueron los de la prenda agraria, de la prenda industrial y de la prenda de automóviles comprados a plazo. Las dos primeras tuvieron un explícito fin de fomento de las respectivas actividades. Para favorecer la agricultura, quedó permitido que el empresario agrícola pudiera pignorar sin entregar sus equipos y maquinarias agrícolas y los frutos de la explotación de la tierra para garantizar créditos conseguidos, generalmente de los bancos, que se destinarían a mejorar y aumentar la misma explotación agraria. Algo semejante acaeció en el ámbito de la industria fabril, en orden a autorizar que los empresarios de ese sector pudieran pignorar sin entrega las maquinarias y equipos de sus empresas, y el producto fabril mismo, como garantía de créditos que conseguirían para incrementar y mejorar la industria. En el caso de la prenda del automóvil comprado con pago diferido de su precio en cuotas periódicas y recibido de inmediato por el comprador, el intento fue económico, en orden a fomentar la expansión 
segura de la industria y el comercio automovilísticos; y social, en orden a conseguir que la creciente producción de vehículos motorizados llegara a las masas, que no podían comprar al contado tales objetos.

Como quedó dicho, los ejemplos de la prenda agraria, de la prenda industrial y de la prenda del automóvil comprado a plazo fueron los más visibles, pero no los únicos. De hecho, estas prendas, especiales por la ausencia de desplazamiento posesorio, se multiplicaron y el Derecho prendario de cada país se sobrecargó visiblemente y devino en complejo e intrincado.

Se autorizó, pues, la prenda con desplazamiento para determinadas deudas (y, por ende, deudores) y sobre determinados bienes. En Francia, los casos más notables fueron los de la hipoteca de naves (Ley de 19 de diciembre de 1874); el "nantissement" de establecimientos comerciales ("fonds de commerce") sin desplazamiento (Ley de 1 de marzo de 1889); la prenda agraria o agrícola ("warrant agricole"), que versa sobre las cosechas, los animales y los instrumentos de explotación agrícola, que permanecen en poder del deudor (Leyes de 18 de julio de 1898 y de 30 de abril de 1906); la prenda hotelera ("warrant hôtelier"), sobre los instrumentos de la explotación de un hotel (Ley de 8 de agosto de 1913); la hipoteca de aeronaves (Ley de 31 de mayo de 1924); la prenda petrolera ("warrant pétrolier") sobre la existencia ("stock") de petróleo (Ley de 21 de abril de 1932); la prenda sobre automóviles vendidos a plazo (Ley de 29 de diciembre de 1934); la prenda sobre tractores agrícolas vendidos a crédito (Ley de 2 de noviembre de 1941); la prenda industrial ("warrant industriel"), sobre toda clase de materias primas y productos fabriles (Leyes de 12 de septiembre de 1940 y de 12 de junio de 1944), etcétera ${ }^{91}$. Los mencionados "warrants" suelen ser denominados "a domicile", para indicar que, como son sin desplazamiento de los objetos pignorados, permanecen en el domicilio del deudor o del constituyente de la garantía.

Este movimiento lento, empírico, inorgánico ha madurado finalmente sólo en 2006, merced a la Ordenanza No 346, de 23 de marzo de aquel año, que introdujo una reforma general al Derecho de las garantías y dio lugar a la creación de un nuevo libro IV: Des sûretés en el Code, cuyo título $2^{\text {a }}$ se rubrica: Des sûretés réelles.

El sistema novísimamente adoptado distingue una garantía sobre muebles y otra sobre inmuebles. La primera puede ser un "gage" o un "nantissement". El "gage" recae sobre muebles corporales o conjuntos de

${ }^{91}$ Sobre estas figuras, véase: Planiol, Marcel - RiperT, Georges, Traité pratique, XII: "Sûretés réeles", $1{ }^{a}$ parte, cit., p. 249-274. Panorama general: RoвLOT, René, Les sûretes mobilières sans déplacemen, en Le Droit privé Français au milieu du XX siècle. Études offertes à George Ripert (Paris, LGDJ, 1950), II, pp. 362-380. 
tales, sean presentes, sean futuros (artículo 2333 CCFr.); se constituye por escrito (artículo 2336); y debe ser inscrita en un registro especial para poder ser opuesta a terceros la prenda (artículo 2338); la cual puede ser "avec dépossession" o "sans dépossession" de los bienes pignorados, a entera voluntad de las partes (artículo 2337). El "nantissement", en cambio, recae sobre muebles incorporales -o sea, derechos personales- o conjuntos de tales, presentes o futuros (artículo 2355); y se constituye por escrito (artículo 2356) ${ }^{92}$.

Por lo que atañe a las garantías sobre inmuebles, el nuevo sistema distingue una "antichrèse", que importa desposesión del constituyente para que se pague su crédito con los frutos del inmueble (artículo 2387); y una "hypothèque", concebida en términos tradicionales (artículos 2393 y siguientes), aunque se añadieron nuevas modalidades de hipoteca, que aquí no interesan.

Por otro lado, merced a la misma reforma antes citada, las prendas especiales que se habían acumulado en el ordenamiento francés durante la segunda mitad del siglo XIX y el siglo XX fueron incorporadas en el libro $\mathrm{V}$ del Code de Commerce, rubricado: Des effets de commerce et des garanties, título 2a: Des garanties.

De esta manera, después de haberlo abandonado consuetudinariamente primero y legalmente después, el Derecho francés reinstaló en su interior el antiguo pignus conventus o hypotheca romano, constituido por convención sobre muebles, pero sin entrega y, por ende, sin desplazamiento de la cosa pignorada al acreedor, primero como posibilidad especial y excepcional; y en fin como posibilidad general de Derecho común. En 1950, un civilista francés, escribió lo que sigue: "[...] une réforme de notre droit permettrait peut-être d'acheminer les sûretés mobilières sans déplacement vers un destin meilleur que celui des warrants à domicile, qui déçurent l'un après l'autres les grandes espoirs suscités par leur apparition; et l'on verrait se renouveler pleinement en Droit moderne le schéma de l'évolution romaine, qui transforma le gage en hypothèque" ${ }^{93}$. Este deseo tardó cincuenta

${ }^{92}$ Sobre el nuevo Derecho francés de garantías reales, véanse, entre otros: SiMLER, Philippe - Delebecque, Philippe, Droit civil: Les sûretés. La publicité foncière (Paris, Dalloz, s.d. [pero 2004]), pp. 307-663; LegEAIs, Dominique, Sûretés et garanties du crédit (5º edición, Paris, LGDJ, s.d. [pero 2006]), pp. 313 ss.; CabrillaC, Michel y otros, Droit de sûretés (8a edición, Paris, Litec, s.d. [pero 2007]), pp. 367-672.

${ }^{93}$ Ibíd., p. 380: [...] una reforma de nuestro Derecho tal vez permitiría encaminar las seguridades mobiliarias sin desplazamiento hacia un destino mejor que aquel de los 'warrants a domicilio', que uno tras otros decepcionan las grandes esperanzas suscitadas por su aparición; y se vería renovar completamente en Derecho moderno el esquema de la evolución romana, que transformó la prenda en hipoteca”. 
y seis años en hacerse realidad. Pero nosotros sabemos que había sido una realidad hasta su repudio al menos a principios de la Época Moderna; de modo que lo acaecido desde la segunda mitad del siglo XIX fue propiamente un redescubrimiento o un reencuentro y no la instalación de una idea revolucionaria.

[Recibido el 5 y aprobado el 16 de octubre de 2009].

\section{BIBLIOGRAFÍA}

Accursius, Glossa in Digestum Novum (Venetiis, B. de Tortis, 1487, reimpresión en Corpus Glossatorum Iuris Civilis, Augusta Taurinorum, Ex Officina Erasmiana, 1968).

Allgemeines Bürgerliches Gesetzbuch für die gesammten deutscher Erbländer der österreichischen Monarchie (Wien, k[aiserlich]-k[önigliche] Hof- und Staatsdruckerey, 1811).

Allgemeines Landrecht für die Preußischen Staaten von 1794 (edición de Hattenhauer, Hans, Frankfurt am Main - Berlin, Metzner, 1970).

[Anónimo], Libellus de verbis legalibus, en FitTING, Hermann, Juristische Schriften des früheren Mittelalters (1876, reimpresión Aalen, Scientia, 1965).

Baldus, Praelectiones [Commentaria] in quattuor Institutionum libros (Venetiis, 1599, reimpresión en BALDus, Commentaria omnia, Goldbach, Keip, 2004).

Basnage, Henri, Traité des hypothèques divisé en deux parties (2a edición, Rouen, Chez Jean Lucas, 1687).

BERGER, Ioannes Henricus, Oeconomia iuris ad usum hodiernum accomodati (8a edición, Lipsiae, Libr. Weidmann, 1801), I.

Bourjon, François, Le droit commun de la France et la coutume de Paris réduits en principes (Paris, Grangé - Cellot, 1779), I.

Braukmann, Michael, Pignus. Das Pfandrecht unter dem Einfluß der vorklassischen und klassischen Tradition der römischen Rechtswissenschaft (Göttingen, Wallstein, 2008).

Bürgerliches Gesetzbuch für West-Galizien, en Seiner Majestät des Kaisers Franz Gesetze und Verfassungen im Justiz-Sache für die deutschen Staaten der oesterreichischen Monarchie in den ersten vier Jahren seiner Regierung (Wien, kayserlich-königlichen Hof und Staats-Druckerei, 1817).

Bussi, Emilio, La formazione dei dogmi di Diritto privato nel Diritto comune (diritti reali e diritti di obbligazione) (Padova, Cedam, 1937).

Butrigarius, Iacobus, In priman et secundam Veteris Digesti partem (Romae, Typis Lepidi Fatii, 1606, II, reimpresión en Opera Iuridica Rariora, Bologna, A. Forni, 1978, XIV, II).

Cabrillac, Michel y otros, Droit de sûretés, $8^{a}$ edición (Paris, Litec, s.d. [pero 2007]).

CATO, De agricultura.

Code Civil des Français (Édition originale et seule officielle, Paris, Imprimerie de la République, 1804).

Codex Maximilianeus Bavaricus Civilis oder Neu Verbessert und Ergänzt Chur-Bayrisches Land-Recht (München, Johann Jacob Vötter, 1756). 
Codex Theresianus, en Harras, Ritter von Harrasowsky, Philipp, Der "Codex Theresianus" und seine Umarbeitungen (Wien, Druck und Verlag von Carl Gerold's Sohn, 1884), II.

Digesta Iustiniani (edición Mommsen).

Dомaт, Jean, Les lois civiles dans leur ordre naturel, en DOMAT, Jean, les lois civiles dans leur ordre naturel, Les lois civiles dans leur ordre naturel, le Droit public et "legum delectus" (Paris, chez Th. de Hansy, 1735), I.

Du CANGE, Charles du Fresne, Glossarium ad scriptores mediae et infimae Latinitatis (Editio Novissima Insigniter Aucta, Francofurti ad Moenum, Ex Officina Zunneriana, apud Johannem Adamum Jungium. Frankofurti ad Moenum, 1710), IV.

"Entwurf Horten's", en Harras [véase], 1886, IV.

"Entwurf Martini's", en Harras [véase], 1886, V.

FENET, Pierre-Antoine, Recueil complet des travaux préparatoires du Code Civil (Paris, Videcoq, 1836), XV.

FERrIÈre, Claude-Joseph, Dictionnaire de Droit et pratique contenant l'explication des termes de Droit, d'ordonnance, de coutumes et de pratique avec les juridictions de France (nouvelle édition, Paris, Brunet, 1769).

FrezzA, Paolo, Le garanzie delle obbligazioni. Corso di Diritto romano (Padova, Cedam, 1963), II: Le garanzie reali.

GaIUs, Institutiones (edición Baviera)

Grotius, Hugo, Florum sparsio ad jus Iustinianeum (Neapoli, Ex Officina V. Manfredii, 157).

Grotius, The Jurisprudence of Holland, The text Translated with Brief Note and a Commentary by Robert Warden Lee (2a edición, 1953, reimpresión Aalen, Scientia, 1977).

GuZmán Brito, Alejandro, Derecho privado romano (3a reimpresión de la $1^{\mathrm{a}}$ edición, Santiago de Chile, Editorial Jurídica de Chile, 2004), I.

JobBé-Duval, Émile, Étude historique sur la revendication des meubles en Droit Français (Paris, Larosse, 1880).

KASER, Max, Das römische Privatrecht (2a edición, München, Beck, 1971), I: Das altrömische, das vorklassische und klassische Recht.

KRÄMER, Gerd, Das besitzlose Pfandrecht. Entwicklungen in der römischen Republik und im frühen Prinzipat (Wien y otras, Böhlau, 2007).

LEGEAIS, Dominique, Sûretés et garanties du crédit (5º edición, Paris, LGDJ, s.d. [pero de 2006]).

Lenel, Otto, Das Edictum Perpetuum (3a edición, Leipzig, Taunitz, 1927).

LÉvy, Jean-Philippe - CASTAldo, Andrés, Histoire du Droit civil (Paris, Dalloz, s.d. [pero de 2002])..

LÖFFELMANN, Arnd, Pfandrecht und Sicherungsübereignung an künftigen Sachen: Rechtsvergleich zwischen deutschem und römischem Recht (Köln y otras, Böhlau, 1996).

LOYSEL, Antoine, Institutes coutumières (2a edición por Dupin, M. - Laboulaye, E., Paris, Videcoq - Durand, 1846), I.

MentXaca, Rosa, La pignoración de colectividades en el Derecho romano clásico (s.l. [pero Bilbao], Servicio Editorial de la Universidad del País Vasco, s.d. [pero de 1986]).

Odofredus, In secundam Digesti Veteris partem (Lugduni, Johannes Pullon, 1523, reimpresión en Opera Iuridica Rariora, Bologna, Forni, 1968), II, 2. 
Patault, Anne-Marie, Introduction historique au Droit des biens (Paris, Presses Universitaires de France, 1989).

Planiol, Marcel - Ripert, Georges, Traité pratique de Droit civil Français (2a edición, Paris, LGDJ, 1927), XII: "Sûretés réeles".

Pos, A. G., Meubles n'ont pas de suite, en Tijdschrift voor Rechtgeschiedenis/ Revue d'Histoire de Droit, 41 (1941,) 1, pp. 45-58.

POTHIER, Robert-Joseph, Coutumes des duché bailliage et prévôté d'Orléans et ressort de iceux, en Euvres de R.-J. Pothier contenant les traités du Droit Français (edición de Bugnet, M., Paris, H. Plon - Cosse et Marchal, 1861), I.

Pothier, Robert-Joseph, Traité de l'hypothèque, en Euvres de R.-J. Pothier contenant les traités du Droit Français (edición de Bugnet, M., Paris, H. Plon - Cosse et Marchal, 1861), IX

PothiER, Robert-Joseph, Traité du contrat du nantissement, en CEuvres de R.-J. Pothier contenant les traités du Droit Français (edición de Bugnet, M., Paris, H. Plon Cosse et Marchal, 1861), V.

PufEndorf, Samuel, De iure naturae et gentium libri octo (Francofurti et Lipsiae, ex officina Knochio-Eslingeriana, 1759, reimpresión Frankfurt am Main, Minerva, 1967), I.

Robles Velasco, Luis Mariano, Las hipotecas privilegiadas en el Derecho romano (Madrid, Centro de Estudios Registrales, 2005).

Roвlot, René, Les sûretes mobilières sans déplacement, en Le Droit privé Français au milieu du XX siècle. Études offertes à George Ripert (Paris, LGDJ., 1950), II, pp. 362-380.

Rosate, Albericus de, In secundam Digesti Veteris partem commentaria (Venetiis, 1585, reimpresión en Opera Iuridica Rariora, Bologna, Forni, 1977), XXII.

Simler, Philippe - Delebecque, Philippe, Droit civil: Les sûretés. La publicité foncière (Paris, Dalloz, s.d. [pero de 2004]).

VAn Apeldoorn, L. J., Mobilia non haben sequelam, en Tijdschrift voor Rechsgeschiedenis/ Revue de Histoire de Droit, 11 (1932) 2, pp. 133-186.

Wolf, Christian, Ius naturae método scientifica pertractatum (Halae Magdebvrgicae, in Officina Libraria Rengeriana, 1746, reimpresión en Wolf, Christian, Gesammelte Werke, Herausgegeben und Bearbeitet von L. École (y otros), II. Abteilung: Lateinische Schriften, Band 21: Jus naturae, Herausgegeben und Bearbeitet por Marcel Thomann, Hildesheim, Georg Olms Verlagsbuchhandlung, 1968). 